\title{
Mechanical Effects of Galvanic Corrosion on Structural Polysilicon
}

\author{
David C. Miller, William L. Hughes, Zhong-Lin Wang, Ken Gall, and Conrad R. Stoldt
}

\begin{abstract}
The mechanical properties of miniaturized materials depend strongly on their structure, which can be altered by wet chemistry methods common in microsystems postprocessing. In a comprehensive and systematic study, we examine the dissolution of silicon when immersed in various hydrofluoric acid (HF)-based chemistries. Specifically, the frequency of mechanical resonance $f_{R}$ of microcantilever beams is used as a vehicle to examine the corrosion of polycrystalline silicon (polySi). A decrease in $f_{R}$ that occurs as a function of immersion time in HF was measured for microcantilevers as well as "comb drives" in contact with a noble metal (gold). Time-dependent variation was also observed in the modulus and hardness measured during indentation testing, sometimes with pronounced difference for specimens contacted to gold. Secondary sources of influence, such as in-plane-oriented residual strain (which remained unchanged), through-thickness-oriented residual strain gradient (increased away from the substrate), and electrical resistance (greatly increased) are examined, but were found not to significantly contribute to the decrease in $f_{R}$ of the microcantilevers. Morphological characterization identified attack on the surface along with grain delineation for the polySi, with the formation of a nanoscale porous layer at the near surface. The damage to the microcantilevers can be modeled by approximating the beams as a laminated composite structure. Such analysis suggests that damage, induced as the result of galvanic corrosion, results from the decreased stiffness of the near surface porous silicon (PS) layer as well as a change in the effective thickness of the beams. Last, corrosion damage is compared between eight representative HF-based chemistries. The measurements here suggest that the fabrication and postprocessing of microsystems components are important, because they can greatly influence the material properties, design, performance, lifetime, tribology, manufacture, and required operating environment of microscale and nanoscale devices.

[2006-0053]
\end{abstract}

Index Terms-Corrosion, gold, microelectromechanical devices, reliability, silicon.

\section{INTRODUCTION}

$\mathbf{T}$ HE fabrication and assembly of microscale and nanoscale sensors and actuators utilizes chemical processing steps for the realization of mechanically freestanding devices.

Manuscript received March 23, 2006; revised June 28, 2006. This work was supported by the University of Colorado at Boulder and Sandia National Laboratories. Subject Editor S. (Mark) Spearing.

D. C. Miller and C. R. Stoldt are with the Department of Mechanical Engineering, University of Colorado, Boulder, CO 80309 USA (e-mail: dcm@colorado.edu).

W. L. Hughes was with the School of Materials Science and Engineering, Georgia Institute of Technology, Atlanta, GA 30332 USA. He is now with California Polytechnic State University, San Luis Obispo, CA 93407-0005 USA.

Z.-L. Wang is with the School of Materials Science and Engineering, Georgia Institute of Technology, Atlanta, GA 30332 USA.

$\mathrm{K}$. Gall is with the School of Materials Science and Engineering and the Woodruff School of Mechanical Engineering, Georgia Institute of Technology, Atlanta, GA 30332 USA.

Color versions of one or more of the figures in this paper are available online at http://ieeexplore.ieee.org.

Digital Object Identifier 10.1109/JMEMS.2006.886028
Specifically, aqueous hydrofluoric acid (HF) solutions are commonly used to dissolve sacrificial silicon dioxide $\left(\mathrm{SiO}_{2}\right)$ layers, thereby "releasing" structural layers comprised of other materials. Early studies hint at the possibility that such wet processing may result in adverse effects in device performance. For example, with the immersion of polycrystalline silicon (polySi) in HF, the modulus and fracture strength were found to vary with acid concentration, grain morphology, and exposure time [1]. Here, immersion in buffered and vaporous HF was found to affect doped polySi films, whereas use of undiluted (48\%) HF or undoped polySi was inconsequential. Another study demonstrated an increase in mechanical modulus, decrease in burst pressure, and decrease in residual stress for square polySi membranes immersed in undiluted, water diluted, and buffered HF solutions [2]. A later study demonstrated morphology changes similar to stress corrosion cracking for polySi layers immersed in HF [3]. In this paper, delamination of adjoined polySi layers and blistering at the interface with phosphosilicate glass (PSG) or low-temperature oxide (LTO) layers occurred for annealed (both doped and undoped) polySi layers soaked in HF. Time-dependent increase in electrical resistance was observed for polySi immersed in $\mathrm{HF}$ as part of a flip-chip bonding assembly process [4]. Decrease in thickness, increase in curvature, and increase in residual stress were observed for polySi soaked in HF [5]. In another study, the low fracture strength of polySi was attributed to the formation of $\sim 50$-nm diameter critical flaws, formed during the etching of the oxide in the HF solution [6]. A duplicate study demonstrated a change in surface roughness (accomplished through grain delineation), decrease in fracture strength, and alteration of fracture morphology for polySi immersed in HF for extended periods of time [6], [8], [9]. Some of these specimens were later studied using transmission electron microscopy (TEM) and demonstrated the formation of amorphous surface layers at the top and bottom of polySi, with internal veins of porous polySi [9], [10]. Last, change in the fracture and fatigue properties of single crystal Si were found to be associated with the presence of a 40-80-nm-thick porous surface oxide layer formed as the result of exposure to HF [11]. In summary, many of the aforementioned studies make use of phosphorus-doped Si [1], [3]-[11], but mechanical property variations are reported in undoped materials as well [2], [6]. Despite the indication of significant alteration in performance, there is currently very limited knowledge concerning the corrosion of polySi in the HF-based chemistries commonly used to remove $\mathrm{SiO}_{2}$.

The addition of an electrical bias has been shown to further enhance damage via an electrochemical corrosion process. For example, metallic contacts were incorporated [4]-[6], [8]-[11] and linked to accelerated damage in polySi structures soaked in various HF solutions. By comparison, Si wafers 
(a)

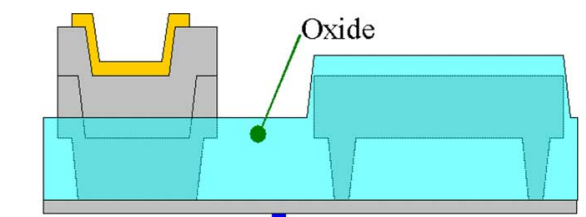

(b)

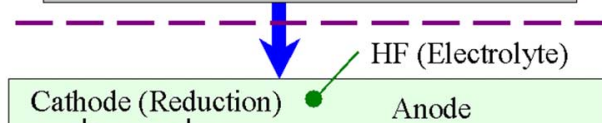

(c)
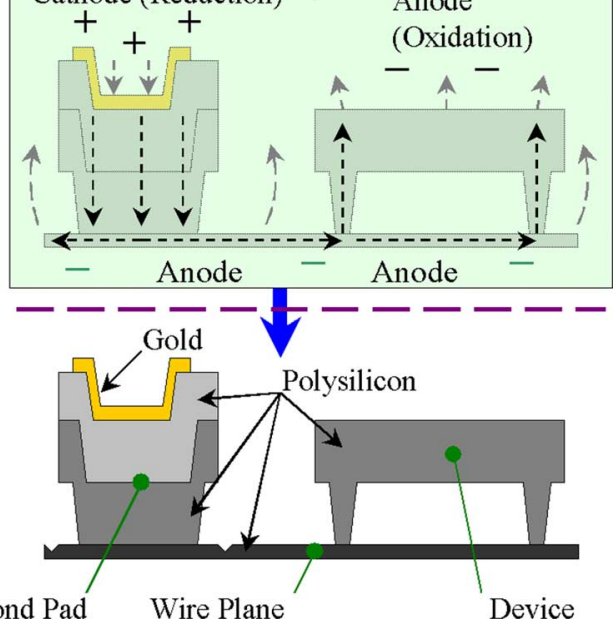

Fig. 1. History of a corroded specimen: (a) initial as-fabricated bond-pad, wiring, and device, (b) creation of a galvanic cell facilitated through ionic current at interfaces and electrical current within materials, and (c) final postprocessed corroded device with components and materials labeled.

patterned with metallic contacts were etched autonomously during immersion in $\mathrm{HF}$ solution, according to a galvanic corrosion process [12]-[14]. A galvanic cell develops when any two materials of different electrochemical potential are brought together in an electrolytic solution, creating a spontaneous oxidation-reduction reaction. For instance, consider a gold-contacted polySi device immersed in an aqueous HF solution (Fig. 1). The device is initially fabricated to consist of structural polySi as well as sacrificial $\mathrm{SiO}_{2}$ layers, with the latter being dissolved through soaking in an HF-based solution [Fig. 1(a)]. Once immersed, the oxidizing agent (e.g., dissolved oxygen in solution) is reduced at the gold surface (the cathode), inducing electrical current flow that initiates oxidation at all polySi free surfaces (the anode) [Fig. 1(b)]. An anodic current is driven by the difference in electrochemical potential between the component materials, and its magnitude is proportional to the relative exposed surface areas of the cathode and anode. In Fig. 1(b), the physical direction of flow for electrons as well as cations is towards the cathode. The galvanic cell thus results in unintended damage to the miniaturized device [Fig. 1(c)]. Damage may include discoloration or visual contrast change at the materials' free surfaces as well as localized material removal [Fig. 1(c)]. In theory, two differently doped polySi layers can generate a galvanic cell, because of their intrinsically different electrochemical potential.

While the self-induced corrosion of polySi structures is not widely studied, a wealth of information is available concerning the externally driven corrosion of single crystal $\mathrm{Si}$, commonly used to create porous silicon (PS) [15]-[17]. To generate nearsurface porosity, an external electrical bias is applied to single crystal Si wafers immersed in an HF-based solution. If sufficient electrical potential is present, Si may be dissolved directly into the electrolytic solution, resulting in PS. The dissolution of $\mathrm{Si}$ is thought to occur according to the reactions [18], [19]

$$
\begin{aligned}
& \mathrm{Si}+2 \mathrm{~F}_{\mathrm{ab}}^{-}+4 \mathrm{HF}_{\mathrm{aq}}+\lambda \oplus \rightarrow \mathrm{H}_{2} \mathrm{SiF}_{6}+\mathrm{H}_{2, \mathrm{aq}}+(2-\lambda) e^{-} \\
& \quad \lambda \leq 2 \\
& \mathrm{Si}+4 \mathrm{HO}_{\mathrm{ab}}^{-}+\lambda \oplus \rightarrow \mathrm{SiO}_{2}+2 \mathrm{H}_{2} \mathrm{O}+(4-\lambda) e^{-}, \quad \lambda \leq 4 \\
& \mathrm{SiO}_{2}+6 \mathrm{HF}_{\mathrm{aq}} \rightarrow \mathrm{H}_{2} \mathrm{SiF}_{6}+2 \mathrm{H}_{2} \mathrm{O}
\end{aligned}
$$

In (1) and (2), the subscript ab denotes the surface-adsorbed ion species, the subscript aq denotes the aqueous species, while $\oplus$ and $e^{-}$represent the holes and electrons, respectively. Reactions (1) and (2) may occur simultaneously on the surface, with (1), i.e., PS formation, dominating for lesser anodic currents. The anodic current can be increased until it reaches a threshold value, distinguishing between the PS formation and electropolishing regimes. In the electropolishing regime, a thick surface oxide forms at a faster rate than at which it can be dissolved. Electropolishing, represented in (2), results in a coarse consumption of $\mathrm{Si}$, as the entire free surface of the anode becomes covered in oxide, which is vulnerable to HF. Much of the study of PS may apply at least in part to polySi, since the generation of PS has been observed for externally biased polySi thin films [20]-[22]. External anodization, when applied to polySi, yielded a nanoporous surface layer above a voided bulk material that itself contained nanoporous regions along grain boundaries [20]. The morphology observed in externally biased polySi thin films was similar to the morphology observed in metallized polySi structures [7]-[10].

Use of external bias or metallization is not necessary to corrode Si. Prolonged exposure to water diluted or undiluted HF was found to produce etch pits on Si wafers [23], [24]. The amount of doping, particularly in n-type $\mathrm{Si}$, can also influence the morphology of Si removal, since the dopant concentration influences the charge and current density characteristics around the material [19]. The corrosion rate for the wafers may also be enhanced by trace (parts per million or less) metallic contaminants in the solutions [27]. The metallic ions are thought to facilitate localized galvanic cells, preferentially initiating corrosion when they become situated adjacent to the defects at the surface of Si. Localized pitting was minimized when hydrochloric acid $(\mathrm{HCl})$ was added to $\mathrm{HF}$ solutions containing trace amounts of various metallic contaminants [27]. Furthermore, $\mathrm{HCl}$ was found to influence PS morphology and uniformity when added to HF-based solutions [28].

For a galvanic cell, certain methods may be used to promote the cathodic reaction by increasing the anodic current. For example, the rate of corrosion may be increased if the surface area of the metal is increased with respect to that of the $\mathrm{Si}$, the concentration of the oxidizing agent is increased, the circulation of the oxidizing agent is increased (through stirring), the ambient temperature is increased, or a more noble metal is used (according to the galvanic series for the electrolyte). Also, the presence of stronger oxidizing agents such as hydrogen peroxide $\left(\mathrm{H}_{2} \mathrm{O}_{2}\right)$ or nitric acid $\left(\mathrm{HNO}_{3}\right)$ will increase the rate of corrosion, respectively [15]. Last, many authors have noted that, especially for n-type single crystal $\mathrm{Si}$, illumination is required, and that the rate of corrosion may be proportional to the extent 
of illumination [14], [15], [26]. Illumination is thought to facilitate the cathodic reaction through the spontaneous generation of electron and hole pairs at the electrolyte interface.

For lesser anodic current, corrosion is typically limited by the cathode, for example, by the supply of oxidizing agent to the metal. For greater anodic current, corrosion is typically limited at the anode, for example, by the supply of fluoride ions to the $\mathrm{Si}$. The rate of the corrosion can be increased through the use of a surfactant, such as ethanol, acetic acid [15], [29], or triton-X-100 [13], [30], [31]. Note that the hydrogen-terminated surfaces typically formed on $\mathrm{Si}$ immersed in $\mathrm{HF}$ are naturally hydrophobic, therefore, the use of a surfactant naturally improves the wetting of an aqueous solution, increasing its interfacial qualities. The use of a surfactant is also thought to facilitate corrosion by helping to remove hydrogen bubbles generated during the anodic reaction. Use of ultrasonic agitation to remove $\mathrm{H}_{2}$ gas bubbles is also noted in the literature [32].

Previous research has suggested the possibility of the alteration in performance for polySi structures immersed in HF-based solutions. Unforeseen effects may be significant, and require greater understanding because the related technology is currently being commercialized as well as being integrated into many other fields of study. For example, it is of utmost importance to know if galvanic corrosion affects the mechanical modulus of polySi utilized in microsystems devices. To answer this question, we have developed a set of test structures to characterize the mechanical resonance, etch rate, through-thickness-oriented strain gradient, in-plane-oriented strain, electrical conductivity, elastic modulus, hardness, and material morphology as a function of postprocessing conditions. The aforementioned performance parameters were investigated for phosphorus doped polySi immersed in electrolytic solutions containing the chemicals commonly used to remove $\mathrm{SiO}_{2}$, including: aqueous and vaporous $\mathrm{HF}$, ethanol, $\mathrm{HCl}$, water, ammonium fluoride, and triton-X. In addition, we have utilized structures with and without gold metallization layers, to ascertain the effect of intrinsic potential from the constituent materials on the corrosion behavior, material structure, and resulting properties. The goal of this research is to systematically investigate if changes in modulus have occurred as the result of immersion in HF solutions and to distinguish such a change in modulus from other sources of influence.

\section{EXPERIMENTAL}

Specimens were fabricated using the multiuser MEMS process (MUMPS), provided by the MEMSCAP Corporation, Research Triangle Park, NC, [37]. The process can be used to create structures having one fixed and two movable polySi layers. In the process, $n$-type wafers are first passivated using an insulating silicon nitride $\left(\mathrm{Si}_{3} \mathrm{~N}_{4}\right)$ layer and then coated with alternating surface micromachined layers of PSG and polySi. Various high-temperature anneals at $1050{ }^{\circ} \mathrm{C}$ serve to transform the as-deposited amorphous $\mathrm{Si}$ into low-stress polySi as well as to diffuse phosphorus dopant from the PSG into the polySi. Next, the $0.5-\mu \mathrm{m}$-thick metal layer is deposited using low-temperature e-beam evaporation and then patterned using a liftoff procedure. Nominal resistivity of the $0.5-, 2.0-$, and $1.5-\mu \mathrm{m}$-thick poly- 0 , poly- 1 , and poly- 2 layers is $0.015,0.020$, and $0.030 \Omega \cdot \mathrm{cm}$, respectively; therefore, the dopant concentration in the different layers is on the order of $10^{20}$ atoms $/ \mathrm{cm}^{3}$, i.e., highly doped [38]. Specimens examined were fabricated in the 61st, 63rd, and 64th MUMPS fabrication runs.

The "release" procedure used to free the structural layers consists of the following steps. First, the specimens are soaked in two consecutive baths of acetone for $10 \mathrm{~min}$ each in order to remove a protective photoresist overcoat. Next, the parts are submerged in isopropyl alcohol for 2 min to clean and remove any residual acetone. The parts are then soaked in deionized water (DI) for $2 \mathrm{~min}$ to remove the isopropanol. To dissolve the PSG sacrificial layers, an HF-solution-based etch is performed for separate intervals. That is, separate chips were removed from the solution after different time durations, to characterize time dependencies. After HF immersion, specimens are soaked in a (4:1) methonal: DI volumetric mixture for $10 \mathrm{~min}$ to remove and dilute any residual HF. The parts are then soaked in pure methanol for $15 \mathrm{~min}$. Last, specimens are supercritically dried from the methanol solution using $\mathrm{CO}_{2}$ to prevent surface-tension-induced adhesion (i.e., "stiction") [40].

The HF used in the first experiments was nominally $48 \% \mathrm{HF}$ in water $\left(\mathrm{H}_{2} \mathrm{O}\right)$, which is the greatest concentration available in semiconductor grade, and is hereafter referred to as "undiluted HF" (UDHF). In addition to its most basic form, HF was combined with other chemicals to investigate their influence upon the polySi (Table I). The motivation, mixture, and times examined are listed in Table I. Uniquely, the vapor HF specimens were first subject to HF exposure in a chamber at MEMSCAP, Inc. The vapor HF specimens were then exposed to the entire solvent series (release procedure, acetone through methanol) at the University of Colorado, however, the specimens were not reexposed to HF. Last, the light present during all wet chemical etching consisted of the ambient fluorescent lighting used in the cleanroom and the wet bench area, plus a $60-\mathrm{W}$ tungsten lamp, which was situated above the HF-based chemical baths.

A series of test structures was created using the MUMPs in order to systematically characterize the effects of galvanic corrosion upon micromachined devices. Microcantilever beams can be used to characterize the through-thickness-oriented strain gradient (TTSG), i.e., curvature, associated with the structural polySi layers [41]. The microcantilevers can also be made to actuate downwards, if a bias is applied between the beams and the Si substrate. Mechanical resonators ("comb drives") [36] can be used to study the in-plane modulus of the polySi using electrostatic actuation [Fig. 2(a)]. Pointer structures [Fig. 2(b)] may be used to estimate the in-plane strain (IPS) present within a structural material layer [41], [42]. The resolution of the pointer structures used in this paper is 28 microstrain $(\mu e)$, i.e., $\sim 4.5 \mathrm{MPa}$. The pointer structure measurements are valid so long as no significant TTSG exists within the material layer. A series of traces was fabricated to investigate the influence of the galvanic corrosion on electrical resistivity [Fig. 2(c)]. The traces were terminated at both ends by wire bond pads, the same as that used for the resonators [Fig. 2(a)]. The width of the poly- 0 traces was fixed at $4 \mu \mathrm{m}$, with the surface area ratio (SAR) of 1.17, 1.13, 0.80, and 0.21 (gold : polySi) for the traces of said geometry. That is, all traces have an equivalent area of metallization with different amounts 
TABLE I

SUMMARY OF CHEMISTRIES USED IN THE EXPERIMENTS

\begin{tabular}{|c|c|c|c|c|c|c|}
\hline Chemistry & Purpose & Constituents & Mixture & Basis & $\begin{array}{c}\text { Etch Times } \\
\text { \{min\} }\end{array}$ & $\begin{array}{c}\text { MUMPS } \\
\text { Run }\end{array}$ \\
\hline \hline Undiluted HF & Most concentrated form & $\mathrm{HF}: \mathrm{H}_{2} \mathrm{O}$ & $48 \%$ & Weight & $5,10,15,20,25,90$ & 61 \\
\hline Hydrochloric acid & Attacks metals/impurities in solution & UDHF: $\mathrm{HCl}$ & $4: 1$ & Volumetric & $5,10,20,30,40,90$ & 61 \\
\hline Ethanol & Surfactant. Used for porous silicon. & UDHF: $\mathrm{C}_{2} \mathrm{H}_{6} \mathrm{O}$ & $4: 1$ & Volumetric & $5,10,20,30,40,90$ & 61 \\
\hline Ethanol & Surfactant. Used for porous silicon. & UDHF: $\mathrm{C}_{2} \mathrm{H}_{6} \mathrm{O}$ & $1: 1$ & Volumetric & $10,20,30,40,90$ & 63 \\
\hline DI water & Dilutant, oxidizing agent. Used in BOE. & UDHF: $\mathrm{H}_{2} \mathrm{O}$ & $1: 1$ & Volumetric & $10,20,30,40,90$ & 63 \\
\hline Ammonium flouride & Buffer the acidity. Used in BOE. & UDHF:NH $\mathrm{H}_{4} \mathrm{~F}$ & $1: 1$ & Weight & $10,20,30,40,90$ & 63 \\
\hline Triton-X-100 & Surfactant. Used for porous silicon. & UDHF:Triton & $20: 1$ & Volumetric & $10,20,30,40,90$ & 64 \\
\hline Vapor HF & Vaporous, not aqueous & HF & 100 & Phase & $15,30,60$ & 64 \\
\hline
\end{tabular}

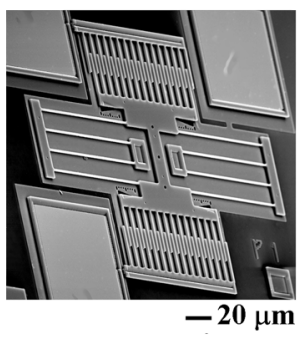

(a)

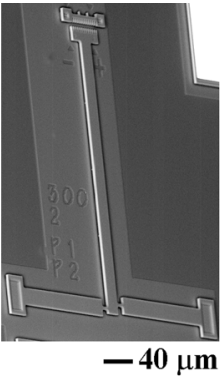

(b)

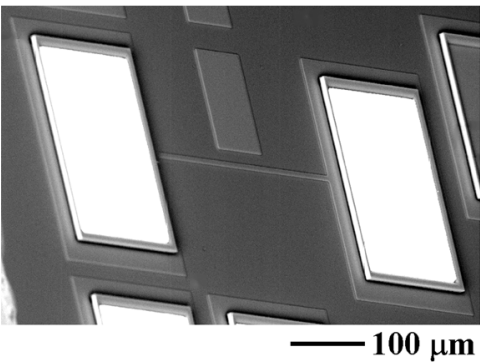

(c)

Fig. 2. Micromachined test structures include (a) electrostatically driven resonators, i.e., "comb drives," (b) pointers, and (c) electrical traces.

of exposed polySi. The nominal resistance for the trace test structures of lengths $5,50,510$, and $4810 \mu \mathrm{m}$ is $0.15,1.50$, 15.26 , and $144.30 \mathrm{k} \Omega$, respectively. Last, circular regions of polySi, $150 \mu \mathrm{m}$ in diameter, were fixed directly to the substrate and utilized as designated indentation sites.

The experiments here (Table I) make use of otherwise identical test structures with and without metal present (Fig. 3). Fig. 3 shows the poly-1 microcantilever structures that have been exposed to a $(1: 1) \mathrm{UDHF}: \mathrm{H}_{2} \mathrm{O}$ mixture for $40 \mathrm{~min}$. Pairs of specimens (microcantilevers, comb drives, pointers, and indentation sites) are manufactured in close proximity to minimize the difference in their fabricated geometry. Specimen pairs are located on the same die ensuring that their chemical exposure is similar, such that they may be compared in a relative manner. When utilized, metal is not deposited directly onto structures, but rather onto an adjacently located interconnect, which is attached using a poly-0 wiring trace. In this way, pairs of specimens with and without metal present can be used to investigate the influence of corrosion for each of the structural material layers. The electrical traces [Fig. 2(c)] are the only exception to the philosophy of the experiments, since only the poly- 0 layer was examined and metal was always present on the electrical interconnects located at both ends of the structures.

The new view 200 interferometric microscope (ZYGO Corporation, Middlefield, CT) used for curvature characterization is capable of accurate surface profiling. The vertical resolution of the machine is better than $1 \mathrm{~nm}$. Lateral resolution for the 10x objective at nominal magnification is approximately $1.18 \mu \mathrm{m}$. Thus, for the beams studied, the measurement accuracy is expected to be better than $3 \%$. After low-pass filtering, the full-field topography profiles were converted to curvature by fitting a second-order polynomial to a user-specified one-dimensional (1-D) cross section of the scan and then taking

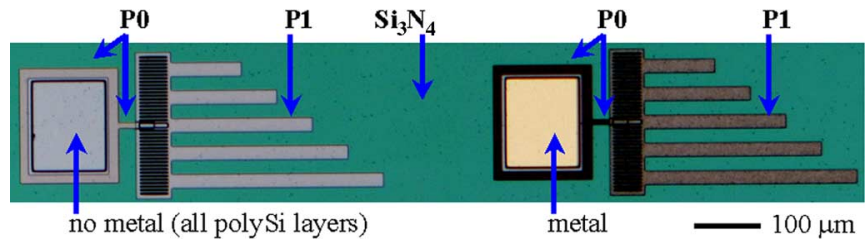

Fig. 3. Optical micrograph of a pair of poly-1 microcantilever test specimens Otherwise, identical specimens with and without metal present on the external electrical interconnects ("bond pads") are located adjacently on the same die. Bond pads are constructed out of all polySi layers and connected to test structures using poly-0 wiring.

the second derivative of the polynomial fit. The sign convention assumed for the measurements is such that when the free end of the beam deflects upwards, away from the substrate, a positive curvature value exists.

Mechanical resonance measurements were performed on a D2414/4 vacuum probe station (MMR Technologies Inc., Mountain View, CA) at pressures $\leq 15$ mTorr, thereby enhancing the quality factor $(Q)$ of the resonance. An HP 33120A waveform generator (Agilent Technologies Inc., Santa Clara, CA) was used to actuate the microcantilevers and resonators. A 112545 laser (Coherent Inc., Santa Clara, CA) was used to generate a beam entering the vacuum chamber through a quartz window and reflecting off of the microcantilever specimens. The laser, with a spot size estimated to be as small as $75 \mu \mathrm{m}$, enabled the microcantilevers to be measured individually. By observing the shape of the laser spot, it is possible to identify the resonant frequency, since the spot would visually stigmate at the resonant frequency $f_{R}$. For the shortest microcantilevers, $f_{R}$ could be determined to within $\pm 0.05 \%$, i.e., $Q$ of $>1000$. For the comb drives, the resonant frequency could be visually determined to within $\pm 0.17 \%$, i.e., $Q>294$. 
Electrical measurements were performed using two HP 34401 A multimeters (Agilent Technologies Inc.) to separately monitor the current and voltage supplied to an individual trace by several combined voltage-controlled power supplies. A micromanipulator 4000 probe station (Micromanipulator Company, Carson City, NV) was used to achieve electrical contact to the trace specimens. Gold, used on all of the trace specimens, is a material known for its minimal contact resistance of external connectivity [43]. Measurements were made using two fresh probes, with the nominal (probe to probe) resistance being 4.9 $\pm 1.0 \Omega$ when both probes were contacted to a larger gold region. Additionally, the resistance of the auxiliary electrical connection from a bond pad through the substrate to a second bond pad was measured to be $44 \pm 5 \Omega$ for all the specimens exposed to the various HF-based solutions for $90 \mathrm{~min}$. That is, even though the more accurate four-point probe technique is not used [44], the contact resistance of internal and external connectivity, i.e., $50 \Omega$, is even less than that of the specimen of least nominal resistance, i.e., $150 \Omega$.

A nanodynamic contact module (DCM) (MTS Nano Instruments Corporation, Oak Ridge, TN) can be used to indent the materials using a diamond Berkovich tip. When performed in continuous stiffness mode, instrumented indentation can be used to obtain the hardness and modulus of a material throughout its thickness, according to the Oliver-Pharr method [45]. Once the tip has engaged the material's surface, the machine is capable of resolving applied load increments lesser than $1 \mu \mathrm{N}$, with displacement resolution less than $1 \mathrm{~nm}$. For reference, a $\langle 001\rangle$ single crystal of $\mathrm{Si}$, a PS sample (obtained from [33]), and a 57-nm-thick layer of oxide thermally grown on $\mathrm{Si}\langle 001\rangle$ were also indented. To limit the influence of the substrate on measurements, indentation into the polySi specimens was performed no deeper than $20 \%$ of the film thickness, with material property values extracted between $9 \%$ and $11 \%$ of the film thickness. After fused silica calibration, each series of indents was made at a constant (loading) strain rate of $0.050 \mathrm{~s}^{-1}$, similar to the procedure in [46], except that the specimens were loaded and unloaded twice to better characterize possible phase transformation activity [47].

A NOVA Nanolab 200 (FEI Company, Hillsboro, OR) is a focused ion beam (FIB) machine equipped with a field emission scanning electron microscope (FESEM). Contained within an active cancellation cage, the practical resolution of the machine is about $2-5 \mathrm{~nm}$. Imaging was performed at $10,30,100$, and $250 \mathrm{kX}$ magnification to fully explore the surface morphology of the polySi. A dimension 3100 (Veeco Instruments Inc., Woodbury, NY) atomic force microscope (AFM) was used to perform surface scans in tapping mode. The radius of curvature of the RTESP (silicon) tips used is nominally $10 \mathrm{~nm}$. The surface locations were measured twice using $3 \times 3-\mu \mathrm{m}^{2}$ scans with 512 pixels in each direction (i.e., $\sim 6-\mathrm{nm}$ lateral resolution) and then processed using comparative thermal drift compensation, plane fit, and low-pass filter routines.

\section{RESULTS}

First, the results of microcantilever resonance experiments are shown in Fig. 4, which applies to $100-\mu$ m-long cantilever

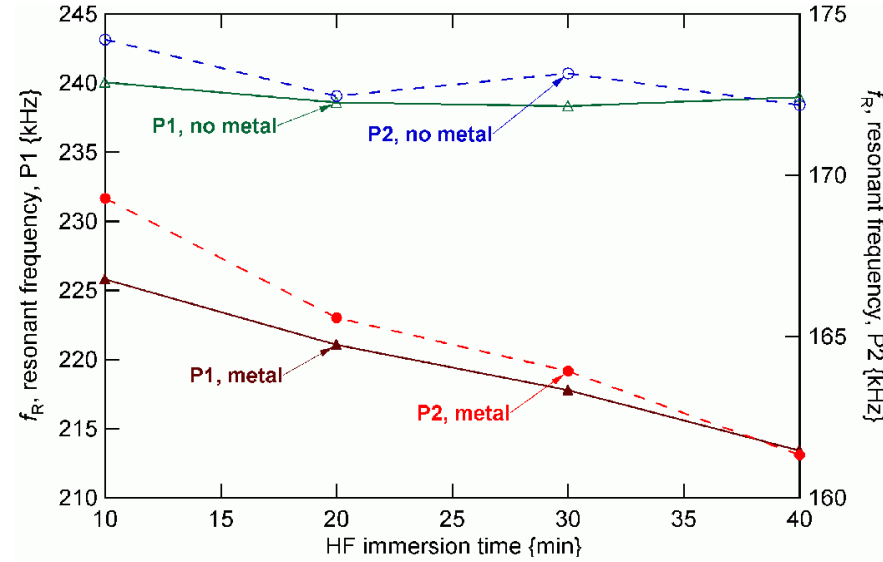

Fig. 4. Cantilever resonant frequency measurements for $100-\mu \mathrm{m}$-long poly-1 and poly-2 beams immersed in $(20: 1)$ UDHF : triton. Specimens not contacted to metal are compared to otherwise identical specimens with metal present at the bond pads.

beams that were immersed in $(20: 1)$ UDHF : triton for various times. In Fig. 4, a time-dependent decrease in $f_{R}$ is measured for the beams in which metal is present relative to beams with no metal present. Decrease in $f_{R}$ for specimens connected to metal was seen in all of the polySi structural materials. In Fig. 4, the impact on the poly-1 layer is more significant compared to the poly-2 layer, which is itself more significant than both layers when laminated together. For example, the ratio of decrease in resonant frequency for microcantilevers immersed in $(20: 1)$ UDHF : triton solution for 10 min was $1: 2.2: 4.5$ for the laminate, poly-2, and poly-1 layers, respectively, when connected to metal. Trends of time and material layer dependence are seen in the experiments for many of the HF-based chemistries utilized, and are further summarized in Table II. Table II compares $f_{R}$ for poly- 1 cantilever specimens and comb-drive structures for all measured data points (immersion times). For each of the chemistries utilized, the relative (percentage) impact is similar between the microcantilever and comb-drive specimens (Table II). In several cases, the comb-drive specimens are more affected than the cantilever specimens. Last, after being immersed in many of the chemistries (Table I) or 40 or $90 \mathrm{~min}$, many of the microcantilevers and resonators did not actuate.

Because material might be removed as a result of corrosion occurring in HF, the thickness of polySi regions with and without metal were compared using the interferometric microscope. If the difference in thickness is divided by the HF immersion time, an etch rate is obtained. Etch rate was measured for the poly- 0 and poly- 1 layers at each of the five different immersion times utilized (Table I). The average data for the poly-0 layer (Table III) was more consistent and at least 3-5 times greater in magnitude than that of poly-1. It is worth noting that in some cases, i.e., the top three rows of Table III, there is not a great statistical significance-no measurable topological difference may exist.

The curvature of the microcantilever specimens was measured prior to resonance testing, in order to eliminate the influence of inadvertent charging of the nitride passivation layer. Curvature, even for specimens when no metal was present, was not always consistent between the fabrication runs 
TABLE II

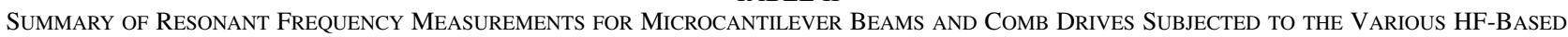
Chemistries. Results Are Shown for the Poly-1 Structural Material Layer, the Most AfFected Layer and Apply to All Data Collected

\begin{tabular}{|c|c|c|c|c|c|c|}
\hline & \multicolumn{3}{|c|}{ Microcantilevers } & \multicolumn{3}{|c|}{ Comb Drives } \\
\hline Electrolytic & $\% \mathrm{D}$ & ase in $\mathrm{Re}$ & $\operatorname{ant} f$ & $\% \mathrm{D}$ & ase in $\mathrm{Re}$ & ant $f$ \\
\hline Solution & AVG & ST DEV & MAX & AVG & ST DEV & MAX \\
\hline UDHF & 1.3 & 0.8 & 2.2 & 4.6 & 2.3 & 6.9 \\
\hline 4:1 (UDHF: $\mathrm{HCl})$ & 0.7 & 0.4 & 1.5 & 2.6 & 1.6 & 5.3 \\
\hline 4:1 (UDHF:Ethanol) & 1.1 & 0.6 & 1.4 & 4.2 & 4.1 & 7.6 \\
\hline 1:1 (UDHF:Ethanol) & 9.2 & 4.1 & 13.5 & 9.0 & 11.5 & 26.1 \\
\hline 1:1 (UDHF: $\left.\mathrm{H}_{2} \mathrm{O}\right)$ & 5.2 & 2.9 & 8.4 & 3.4 & 2.1 & 5.6 \\
\hline 1:1 (UDHF: $\left.\mathrm{NH}_{4} \mathrm{~F}\right)$ & 6.4 & $\mathrm{~N} / \mathrm{A}$ & 6.4 & 11.3 & 19.9 & 41.1 \\
\hline 20:1 (UDHF:Triton) & 8.3 & 2.1 & 11.0 & 9.6 & 1.7 & 11.8 \\
\hline Vapor HF & 0.0 & 0.0 & 0.0 & -0.3 & 0.3 & -0.1 \\
\hline AVG & 4.0 & 1.6 & 5.5 & 5.5 & 5.4 & 13.0 \\
\hline ST DEV & 3.7 & 1.5 & 5.0 & 4.0 & 6.8 & 13.7 \\
\hline
\end{tabular}

TABLE III

SuMmary of ETCH Rates FOR THE POLY-0 LAYER. For EACH CHEMISTRY, THE VALUES ARE AVERAGED FOR ALL IMMERSION TIMES

\begin{tabular}{|c|c|c|}
\hline \multirow{2}{*}{ Etchant } & \multicolumn{2}{|c|}{ Etch Rate $\{\mathrm{nm} / \mathrm{min}\}$} \\
\cline { 2 - 3 } & AVG & ST DEV \\
\hline \hline UDHF & 0.1 & 0.1 \\
\hline 4:1 (UDHF:HCl) & 0.5 & 0.3 \\
\hline $4: 1$ (UDHF:Ethanol) & 0.8 & 1.2 \\
\hline $1: 1$ (UDHF:Ethanol) & 6.5 & 0.7 \\
\hline $1: 1$ (UDHF: $\left.{ }_{2} \mathrm{O}\right)$ & 1.6 & 0.7 \\
\hline $1: 1$ (UDHF: $\left.\mathrm{NH}_{4} \mathrm{~F}\right)$ & 11.3 & 0.6 \\
\hline 20:1 (UDHF:Triton) & 6.4 & 0.6 \\
\hline Vapor HF & 0.1 & 0.1 \\
\hline AVG & 3.4 & 0.5 \\
\hline ST DEV & 4.1 & 0.4 \\
\hline
\end{tabular}

and was somewhat variable even within the same run. Nonetheless, TTSG can be compared between adjacent beams with and without metal present and on a relative (percentage difference) basis. In general, an increase in curvature (directed away from the substrate) was seen for those specimens connected to metal relative to those specimens with no metal present. The change in TTSG due to HF exposure was most significant for poly-2, then poly-1, then the laminated structural layer. Results, the average of all beams according to the different chemistries, are shown in Table IV for the poly-2 layer.

Because an in-plane-oriented strain may affect mechanical resonance, it was characterized next. Measurements of -51.1 , -91.9 , and $-22.8 \mu$ e were obtained for the poly-1, poly-2, and laminate layers, respectively. Assuming a modulus of 161.8 GPa, i.e., the Hill modulus [48] for the material, this corresponds to compressive stresses of 8.3, 14.9, and 3.7 MPa for the respective layers. The measured stress values are minimal, such that the $\leq \pm 11 \%$ difference between the metallized and unmetallized specimens is not significant. The measured stress values are similar to the vendor data measured during each fabrication run [37].

To investigate the possible influence of the cantilever's electrical leads, the current-voltage $(I-V)$ profiles of designated trace test structures were characterized. Fig. 5 shows the results of electrical characterization for electrical trace structures exposed to a $(1: 1)$ UDHF : $\mathrm{H}_{2} \mathrm{O}$ mixture. The trace SAR is 1.13 (gold : polySi). From the $I-V$ profiles, resistance is seen

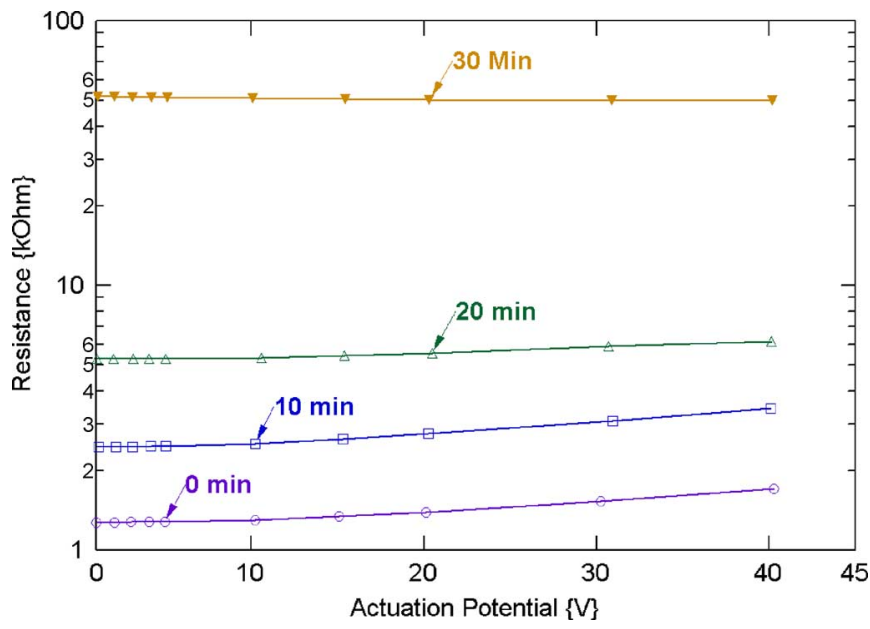

Fig. 5. Electrical characterization for electrical traces of the same geometry exposed to a $(1: 1) \mathrm{UDHF}: \mathrm{H}_{2} \mathrm{O}$ mixture. From the $I-V$ profiles, resistance is seen to increase significantly with time.

to increase 36-fold with time. Note that the specimens exposed to the UDHF: $\mathrm{H}_{2} \mathrm{O}$ mixture for 40 and $90 \mathrm{~min}$ had a greater impedance than that of the test equipment, i.e., $>10 \mathrm{M} \Omega$. Drastic increase (often 20-50X) in resistance was seen for many of the chemistries examined [49]. Lesser increase in resistance was typically seen for the electrical trace structures of the lowest SAR, i.e., those traces with a lesser surface area of gold relative to the surface area of polySi [49].

To better understand the measured change in $f_{R}$, a series of indents was performed on specimens of poly- 0 and poly- 1 , with and without connected metal. Results for the poly- 0 specimens immersed in the $(1: 1)$ UDHF : $\mathrm{H}_{2} \mathrm{O}$ mixture are shown in Fig. 6. Data in Fig. 6 represent the average for each of the respective indentation sets, i.e., 12 indentations. Fig. 6 shows a time-dependent decrease in hardness and modulus for the specimens, with and without metal present. The decrease in hardness and modulus for the specimens with no metal is lesser than that measured for the specimens with metal present. Additionally, there is a substantial offset between those specimens with and without metal present.

Results of indentation testing are further explored in Fig. 7, where Berkovich hardness measurements for several poly-1 specimens with metal present are compared to $\mathrm{Si}\langle 001\rangle$ wafer, 
TABLE IV

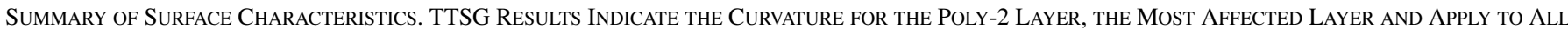

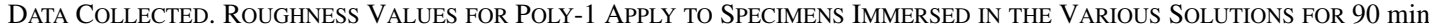

\begin{tabular}{|c|c|c|c|c|c|c|c|c|}
\hline & \multicolumn{4}{|c|}{ Curvature $\{1 / \mathrm{m}\}$} & \multicolumn{4}{|c|}{ Roughness $\{\mathrm{nm}\}$} \\
\hline \multirow{2}{*}{$\begin{array}{l}\text { Electrolytic } \\
\text { Solution }\end{array}$} & \multicolumn{2}{|c|}{ NO METAL } & \multicolumn{2}{|c|}{ METAL } & \multicolumn{2}{|c|}{ NO METAL } & \multicolumn{2}{|c|}{ METAL } \\
\hline & AVG & ST DEV & AVG & ST DEV & Ravg & Rrms & Ravg & Rrms \\
\hline UDHF & - & $\overline{6.9}$ & -54.1 & $\overline{5.6}$ & 3.99 & "5.17 & 4.09 & $\overline{c 5.20}$ \\
\hline 4:1 (UDHF:HCl) & -71.1 & 3.1 & -56.0 & 5.2 & 4.16 & 5.32 & 4.26 & 5.36 \\
\hline 4:1 (UDHF:Ethanol) & -68.9 & 2.8 & -57.6 & 3.1 & $\mathrm{~N} / \mathrm{A}$ & $\mathrm{N} / \mathrm{A}$ & N/A & N/A \\
\hline 1:1 (UDHF:Ethanol) & -11.6 & 2.4 & 19.5 & 5.9 & 7.45 & 9.96 & 8.03 & 10.50 \\
\hline $1: 1\left(\mathrm{UDHF}: \mathrm{H}_{2} \mathrm{O}\right)$ & -8.9 & 1.7 & 10.6 & 2.4 & 9.18 & 11.60 & 7.64 & 9.64 \\
\hline $1: 1$ (UDHF: $\left.\mathrm{NH}_{4} \mathrm{~F}\right)$ & -1.3 & 3.8 & 5.5 & 2.8 & 17.47 & 23.60 & 15.27 & 20.40 \\
\hline 20:1 (UDHF:Triton) & -13.5 & 3.7 & 13.8 & 8.8 & 9.87 & 12.65 & 9.71 & 12.40 \\
\hline Vapor HF & -21.0 & 2.2 & -19.8 & 3.6 & 9.09 & 11.50 & 7.80 & 9.88 \\
\hline AVG & -32.9 & 3.3 & -17.3 & 4.7 & 8.74 & 11.40 & 8.11 & 10.48 \\
\hline ST DEV & 30.3 & 1.6 & 34.0 & 2.1 & 4.53 & 6.17 & 3.77 & 5.12 \\
\hline
\end{tabular}

TABLE V

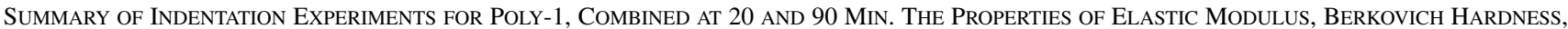
REtained Energy, AND $K_{\exp }$ ARE Compared for Those SPECIMENS With AND Without Metal Present

\begin{tabular}{|c|c|c|c|c|c|c|c|c|}
\hline \multirow{3}{*}{$\begin{array}{c}\text { Electrolytic } \\
\text { Solution }\end{array}$} & \multicolumn{2}{|c|}{ Modulus At Max Load } & \multicolumn{2}{|c|}{$\begin{array}{l}\text { Hardness, } \\
\text { Corrected }\end{array}$} & \multicolumn{2}{|c|}{ Retained Energy Ratio } & \multicolumn{2}{|c|}{$\begin{array}{c}\text { Kexp, } \\
\text { Loading }\end{array}$} \\
\hline & No Metal & Metal & No Metal & Metal & No Metal & Metal & No Metal & Meta \\
\hline & $\{\mathrm{GPa}\}$ & $\{\mathrm{GPa}\}$ & $\{\mathrm{GPa}\}$ & $\{\mathrm{GPa}\}$ & $\{\%\}$ & $\{\%\}$ & $\{\mathrm{GPa}\}$ & $\{\mathrm{GPa}$ \\
\hline Silicon <001> & \multicolumn{2}{|c|}{172.2} & \multicolumn{2}{|c|}{13.0} & \multicolumn{2}{|c|}{43.3} & \multicolumn{2}{|c|}{260.9} \\
\hline $57 \mathrm{~nm} \mathrm{SiO}_{2}$ on $\mathrm{Si}<001>$ & \multicolumn{2}{|c|}{154.8} & \multicolumn{2}{|c|}{13.7} & \multicolumn{2}{|c|}{46.6} & \multicolumn{2}{|c|}{260.1} \\
\hline Porous Silicon & \multicolumn{2}{|c|}{89.8} & \multicolumn{2}{|c|}{2.8} & \multicolumn{2}{|c|}{50.3} & \multicolumn{2}{|c|}{74.1} \\
\hline UDHF & 162.0 & 153.5 & 13.1 & 11.9 & 41.6 & 42.7 & 269.6 & 260.4 \\
\hline (4:1) UDHF: $\mathrm{HCl}$ & 176.4 & 175.6 & 13.3 & 13.5 & 43.6 & 43.7 & 268.6 & 271.5 \\
\hline (1:1) UDHF:Ethanol & 173.3 & 131.3 & 13.4 & 8.3 & 43.4 & 46.2 & 267.9 & 180.2 \\
\hline$(1: 1)$ UDHF: $\mathrm{H}_{2} \mathrm{O}$ & 167.5 & 158.7 & 12.0 & 11.1 & 45.2 & 46.9 & 247.8 & 232.7 \\
\hline$(1: 1)$ UDHF: $\mathrm{NH}_{4} \mathrm{~F}$ & 160.0 & 155.9 & 9.8 & 9.5 & 46.6 & 48.2 & 214.9 & 208.7 \\
\hline$(20: 1)$ UDHF:Triton & $\mathrm{N} / \mathrm{A}$ & $\mathrm{N} / \mathrm{A}$ & $\mathrm{N} / \mathrm{A}$ & $\mathrm{N} / \mathrm{A}$ & $\mathrm{N} / \mathrm{A}$ & $\mathrm{N} / \mathrm{A}$ & $\mathrm{N} / \mathrm{A}$ & $\mathrm{N} / \mathrm{A}$ \\
\hline Vapor HF & 167.8 & 167.3 & 11.7 & 12.0 & 47.6 & 46.4 & 244.7 & 248.1 \\
\hline P1, No Metal & \multicolumn{2}{|c|}{167.8} & \multicolumn{2}{|c|}{12.2} & \multicolumn{2}{|c|}{44.7} & \multicolumn{2}{|c|}{252.2} \\
\hline
\end{tabular}

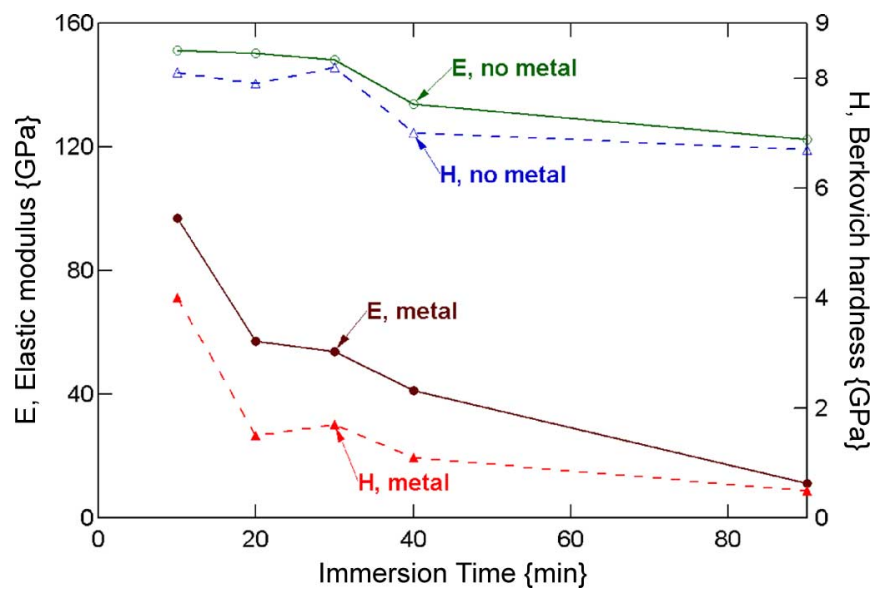

Fig. 6. Indentation characterization for poly-0 layer exposed to a $(1: 1)$ UDHF : $\mathrm{H}_{2} \mathrm{O}$ mixture. For specimens where metal is present, both hardness and modulus are seen to decrease significantly as immersion time is increased.

dry thermal oxide, and PS reference samples. Each data profile illustrated is the median of the measurement set. The poly-1 specimens were immersed in HF-based solutions for $90 \mathrm{~min}$. The hardness of the Si wafer, thermal oxide, and polySi specimen immersed in UDHF are seen to be quite similar. The hardness of the UDHF and $\mathrm{H}_{2} \mathrm{O}, \mathrm{NH}_{4} \mathrm{~F}$, and $\mathrm{C}_{2} \mathrm{H}_{6} \mathrm{O}$ specimens are seen to be decreased throughout the depth range examined,

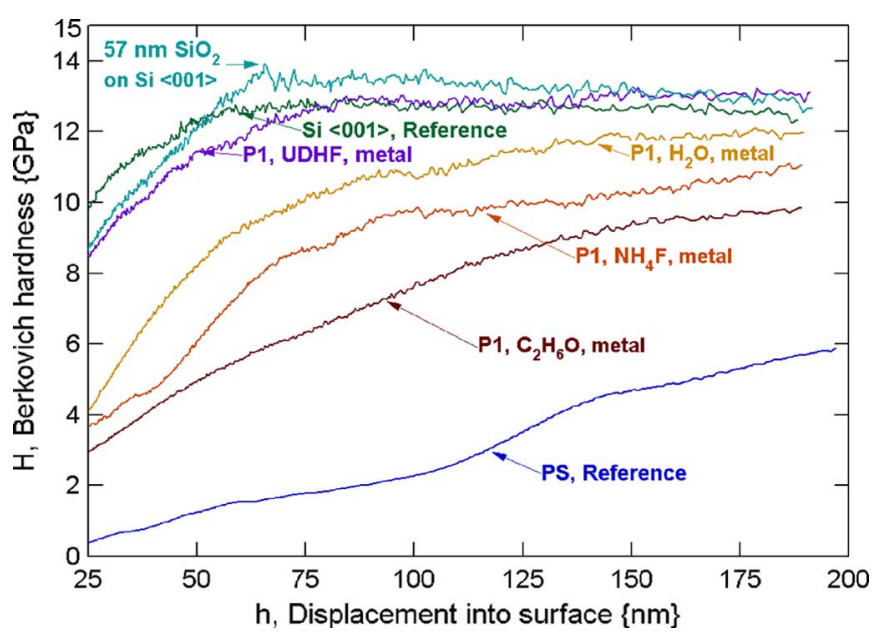

Fig. 7. Berkovich hardness measurements for poly-1 immersed in HF-based solutions for $90 \mathrm{~min}$. Several specimens with metal present are compared to $\mathrm{Si}$ $\langle 001\rangle$, dry thermal oxide, and PS reference samples.

but are always greater than that of the PS reference sample. Note that the thickness of the dry thermal oxide precludes the determination of its exact hardness. However, the data is included here to demonstrate how a thick surface oxide (such as that generated during electropolishing) would influence such measurements. 

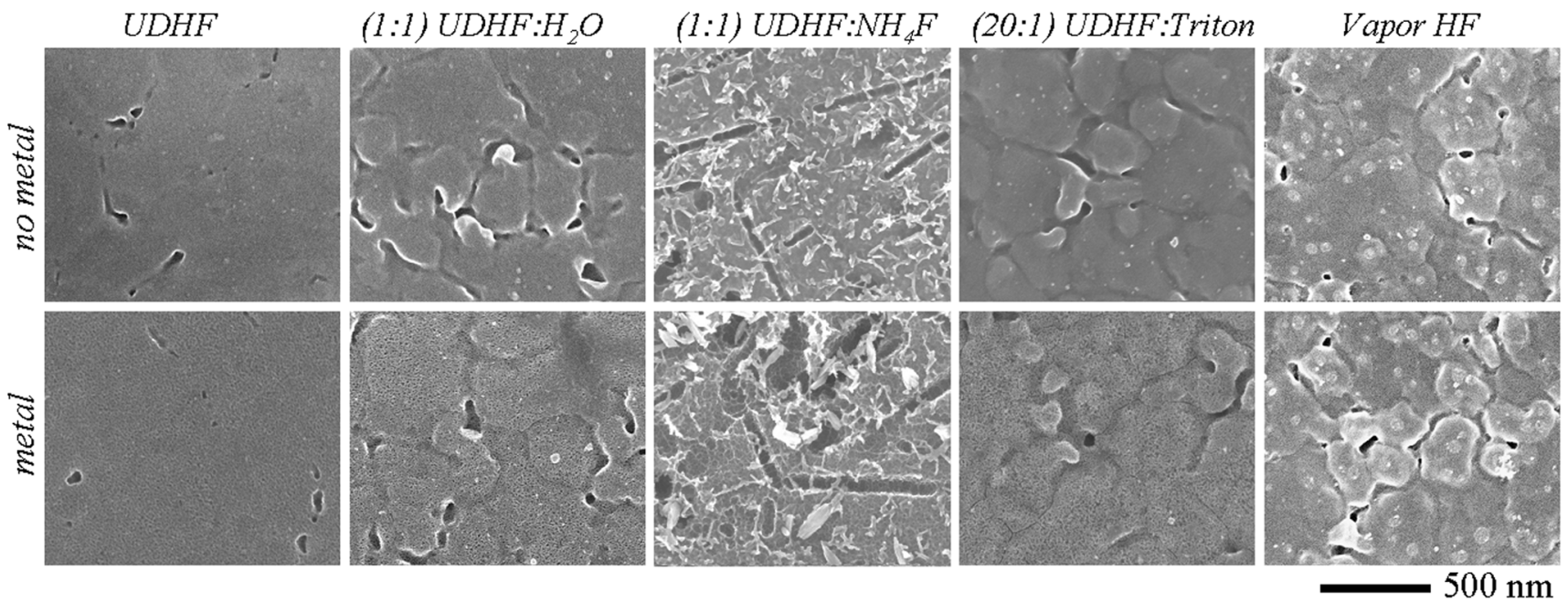

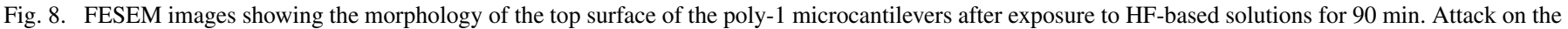
surface and grain delineation can be seen in comparison to the solely UDHF mixture, which is the most similar to the as-deposited morphology.

The indentation results for poly-1 are summarized in Table V. Of the properties measured, values for elastic modulus, Berkovich hardness, retained energy, and $K_{\text {exp }}$ appear in Table V. Most tabulated values were obtained from specimens immersed in HF-based solutions for 20 and 90 min, each indented nine times. The reference specimens, not immersed in HF solutions, were indented 15 times each. In Table V, the retained energy ratio identifies the relative portion of energy that is not recovered when the indentor tip is unloaded, i.e., the inelastic energy. The parameter $K_{\exp }$ may be used to estimate the amount of elastic or inelastic deformation occurring during the indentation loading [50]. $K_{\exp }$ is not the same as the stiffness of the specimen or measurement instrument. Unlike the modulus and hardness measurements, the retained energy ratio and $K_{\exp }$ may be used to quantify hardness and elasticity in a manner that is independent of the area calibration for the indentor tip. In theory, because these parameters do not require tip calibration, they may be less prone to error. For several of the HF-based chemistries, a decrease in modulus, hardness, and $K_{\exp }$ along with an increase in retained energy was measured. For reference, the cumulative property values for poly-1 when no metal was present appear in the bottom row of Table V. Table V could be compared to the results for poly-0 [51]. To summarize that data, when metal was present and the poly- 0 was immersed in $\mathrm{HF}$, it was significantly more affected than poly-1, often being less robust than the PS reference specimen. Also, for poly- 0 , specimens exposed to the $(20: 1)$ UDHF : triton were found to be greatly affected when metal was present (the poly-1 test structures for this chemistry were damaged and could not be indented). For reference, the modulus and hardness of poly- 0 when no metal was present were found to be $147.7 \pm 39.1$ and $8.9 \pm 3.7 \mathrm{GPa}$, respectively.

Electron microscopy was performed on the top surface of the poly- 1 cantilever beams. The top row of Fig. 8 shows the specimens where no metal was present whereas the bottom row of the figure shows the corresponding specimens with connected metal. All specimens in Fig. 8 have previously been exposed to HF-based solutions for $90 \mathrm{~min}$ to render obvious results. For the

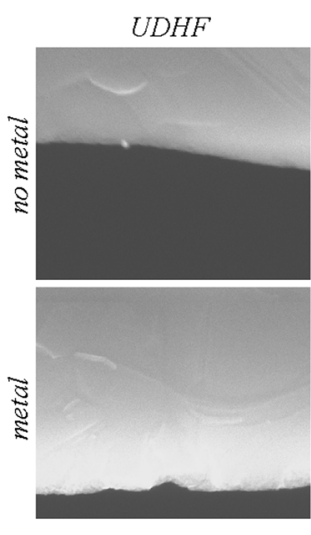

(1:1) $\mathrm{UDHF}: \mathrm{H}_{2} \mathrm{O}$

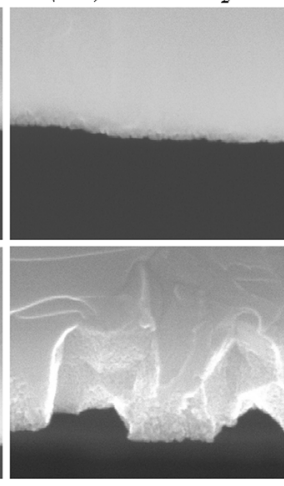

Fig. 9. FESEM images showing the morphology of the surface of the poly-1 microcantilevers after exposure to HF-based solutions for $90 \mathrm{~min}$. The material is seen in cross section after having been fractured and is viewed looking at the edge of the broken surface (the interior of the beam is at the top of the figures).

solely UDHF chemistry (and $\mathrm{HCl}$ mixed solution-not shown), which is most similar to the material in its as-deposited state, the poly-1 layer is seen to have some surface pitting. For many of the other chemistries, including the $\mathrm{C}_{2} \mathrm{H}_{6} \mathrm{O}, \mathrm{H}_{2} \mathrm{O}$, triton mixed solutions as well as vapor $\mathrm{HF}$, attack is evidenced by delineation between material grains. While not all are shown, the grain delineation for the aforementioned chemistries is similar in appearance, with and without metal present. Extreme attack, including grain delineation, linear surface extrusions, and formation of nanowires and nanoparticles is observed for specimens exposed to the UDHF: $\mathrm{NH}_{4} \mathrm{~F}$ chemistry solution, both with and without metal present. For reference, microscopy was also performed on the poly- 0 interconnect wiring [51]. It is worth noting that surface pores roughly $5-10 \mathrm{~nm}$ in diameter were seen on the surface of all of the test specimens, except the for vapor HF solution [51]. Similar sized surface pores were seen on both the poly- 0 and poly- 1 test specimens.

To further investigate the polySi morphology, some of the cantilever beam specimens were fractured using a mechanical 


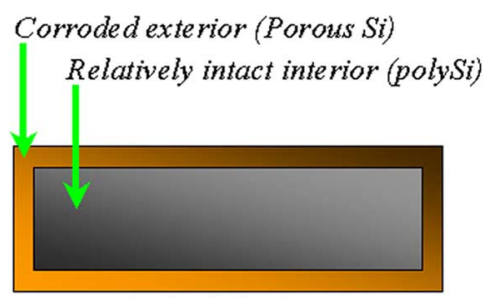

Actual device

(a)

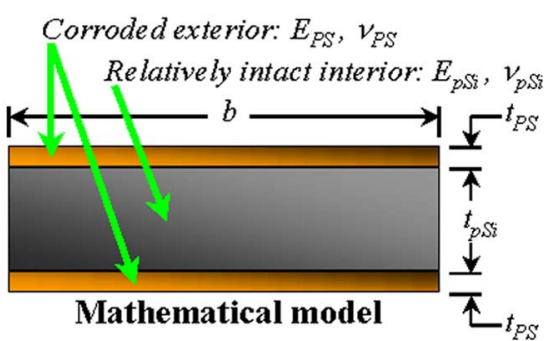

(b)

Fig. 10. Schematic representing (a) cross section of an actual microcantilever and (b) approximated cross section for mathematical representation as a laminated composite. The dimensions and material properties of the corroded (PS) exterior as well as the more intact (polySi) interior are shown.

probe (Fig. 9). Beams were thus fractured in response to an applied bending load, with fracture occurring near the fixed end. Fig. 9 shows the surface morphology of the solely UDHF as well as the $\mathrm{H}_{2} \mathrm{O}$ and $\mathrm{NH}_{4} \mathrm{~F}$ mixed solutions, examining the bottom of the fractured surface, i.e., the surface of the beam nearest to the substrate. The images in Fig. 9 were not obtained near the fracture origin. A roughened texture is observed on the exterior of the beams (center of each image) that is not observed on the interior (top of each image). The roughness of the specimens connected to metal extends at least 50-200 nm into their surface. The $\mathrm{H}_{2} \mathrm{O}$ added chemistry showed the greatest impact, with intrusions into the metallized specimen being as great as $260 \mathrm{~nm}$. The $\mathrm{NH}_{4} \mathrm{~F}$ mixed solution significantly affected polySi with and without connected metal, with surface intrusions as great as 70 and $110 \mathrm{~nm}$, respectively. While not readily apparent in the surface characterization, increased roughness was seen at the surface of the specimen immersed in the solely UDHF solution, when metal was present. For this specimen as well as the $\mathrm{H}_{2} \mathrm{O}$ mixed specimen without metal present, surface pitting was seen up to about 55 and $35 \mathrm{~nm}$, into the respective surfaces. For the solely UDHF chemistry, when no metal was present, there is no obvious corrosion damage.

AFM scans were performed on the flat poly-1 regions also used for indentation, with the quantitative data in Table IV. As in the FESEM work, specimens examined were exposed to their respective HF solution for $90 \mathrm{~min}$, so as to render obvious material damage. Like for the FESEM data, the poly-1 surface is relatively unchanged for the solely UDHF as well as the $\mathrm{HCl}$ mixed solutions. In the scans, attack is visually obvious for the $\mathrm{C}_{2} \mathrm{H}_{6} \mathrm{O}$, $\mathrm{H}_{2} \mathrm{O}$, triton, and vapor $\mathrm{HF}$ solutions, which is manifested in the roughness values. Only partial regions of the $\mathrm{NH}_{4} \mathrm{~F}$ chemistry (with and without connected metal) could be scanned consistently, presumably due to surface contamination of the tip from nanoscale particulates accumulated from the sample. Qualitatively, the AFM scans were wholly consistent with the electron microscopy performed at lesser magnification than in Fig. 8.

\section{ANALYTiCAl Model}

Based on the measured change in $f_{R}$ (Fig. 4 and Table II) as well as the observed damage morphology (Figs. 8 and 9), a mathematical representation of the affected cantilever beams can be constructed. For example, the resonance of a cantilever beam may be related to its material and dimensional attributes. In (3), $f_{R}$ represents the resonant frequency (hertz), $k$ the mechanical spring constant in bending (newton per meter), $E$ the elastic modulus (pascal), $t$ the beam thickness (meter), $I$ the area moment $\left(\mathrm{m}^{4}\right), E I_{\text {equiv }}$ the effective bending stiffness $\left(\mathrm{Pa} \cdot \mathrm{m}^{4}\right)$, $m$ the mass of the beam (kilogram), $\pi$ the mathematical constant, $\rho$ the material density (kilogram per cubic meter), and L the beam length (meter). Apart from its general form [(3), left], the coefficients chosen are suited to represent the fundamental frequency of mechanical resonance for a fixed-free beam. Note that effects such as anchor compliance, anchor takeoff angle, and through-thickness-oriented strain gradient are not considered in

$$
f_{R} \approx \frac{1}{2 \pi} \sqrt{\frac{k}{m}}=\frac{1}{2 \pi} \sqrt{\frac{3 E t^{2}}{\rho L^{4}}}=\frac{\sqrt{3}}{\pi} \sqrt{\frac{E I_{\text {equiv }}}{L^{3}} \frac{1}{m}} .
$$

Equation (3) may be more specifically applied to the situation of corrosion if the beam is represented as a laminated composite [52]. To clarify, consider the cross section of a corroded beam [Fig. 10(a)], which consists of a corroded exterior and relatively unaffected interior. Once corroded, the exterior may consist of a layer of PS with a relatively unaffected interior layer composed of polySi. For simplicity, the sides of the beam may be neglected [Fig. 10(b)]. For a multilayered composite, $E I_{\text {equiv }}$ considers both the axial (bar) and bending stiffness as in [52] and [53]. The mass of the beam may be represented using (4). In (4) as well as in Fig. 10(b), the subscripts PS and $\mathrm{pSi}_{\text {ri }}$ refer to the corroded exterior layers and the interior layer, respectively, and $b$ represents the beamwidth (meter). In (4), the assumption is made that the density of the corroded exterior layer is directly proportional to its mechanical modulus, as in a "rule of mixtures" approximation [52]. If the geometry of a porous surface layer is known, its material properties can be more specifically represented as a honeycomb composite [54]. Note that the corroded surface is assumed to possess uniform thickness at affected surfaces and that the properties of the component layers are assumed to be isotropic and homogeneous. Other assumptions and limitations for the laminated composite approach are described in [52] and [53]

$$
m=\left(2 \frac{E_{\mathrm{PS}}}{E_{\mathrm{pSi}}} \rho_{\mathrm{pSi}} t_{\mathrm{PS}} b L\right)+\rho_{\mathrm{pSi}} t_{\mathrm{pSi}} b L
$$

The analytic representation can be applied to determine the predicted change in $f_{R}$, when the thickness and modulus of the corroded exterior layer are assumed/known (Fig. 11). In the analysis, the modulus of the interior layer was assumed to be 161.8 GPa. Contours in Fig. 11 represent the assumed modulus 


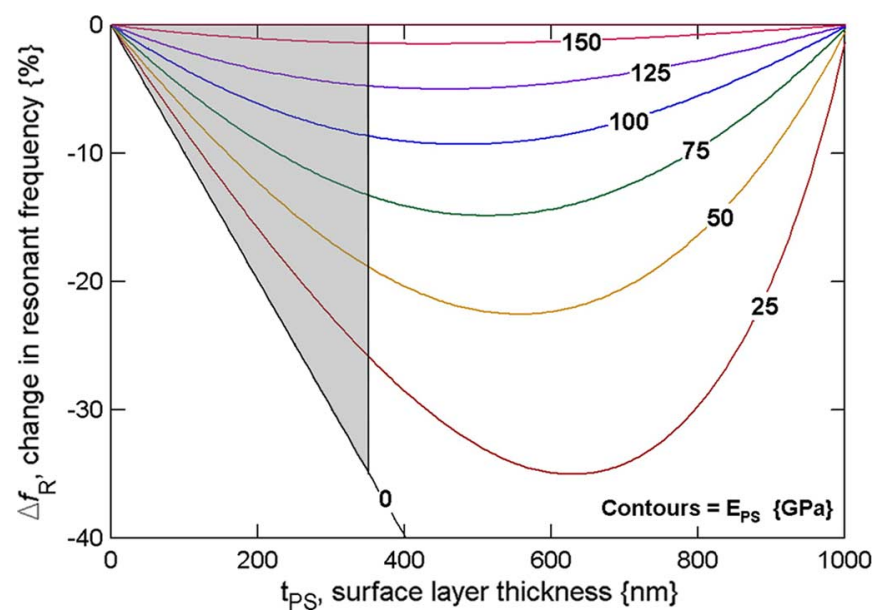

Fig. 11. Results of analysis for laminated composite microcantilever. The results indicate predicted change in resonant frequency if the thickness and modulus of the corroded exterior layer are assumed. The shaded region encompasses the range of the experimental results.

for the corroded exterior. The shaded region in Fig. 11 encompasses the full range of the experimental results. Minimal impact is seen when the modulus of the corroded exterior layer is similar to that of the interior layer (top of Fig. 11), e.g., $E_{\mathrm{PS}}=$ $150 \mathrm{GPa}$. Maximum impact is observed when the modulus of the corroded exterior layer is greatly reduced relative to that of the interior layer (bottom of Fig. 11). The bottommost contour $E_{\mathrm{PS}}=0$ represents a decrease in beam thickness. While not shown, $f_{R}$ will be decreased by $100 \%$ for $E_{\mathrm{PS}}$ of $0 \mathrm{GPa}$ and thickness of $1000 \mathrm{~nm}$, i.e., complete material removal. The profiles in the middle of Fig. $11 E_{\mathrm{PS}}=25-125 \mathrm{GPa}$ are dominated either by the decrease in mechanical stiffness (left of Fig. 11) or the loss of mass (right of Fig. 11).

\section{DISCUSSION}

Table VI quantitatively ranks the experimental results based on the maximum and minimum difference between the specimens exposed to the various HF-based chemistries. First, the magnitude of decrease in $f_{R}$ is significant (Fig. 4 and Table II), often being greater than $1 \%$ or $2 \%$, i.e., the expected accuracy in rudimentary measurement equipment. A decrease in $f_{R}$ directly correlated with immersion time in an HF-based solution was exacerbated when adjacent metal contacted the polySi test structures. Therefore, it is argued that the decrease in $f_{R}$ is associated with the electrochemical corrosion of the structural polySi layer(s). For example, decrease in $f_{R}$ can be caused by degradation of the material (increased porosity-decrease in modulus), removal of material, or alteration of the material (chemical reaction-oxidation) as the result of PS formation or electropolishing. By examining the various experiments summarized in Table VI, as well as the literature, the factors that primarily influence $f_{R}$ can be determined leading to a greater understanding of the corrosion phenomenon.

While decrease in $f_{R}$ was measured for both microcantilever and comb-drive structures (Tables II and VI), the magnitude of change is often greater for the comb-drive structures. The greater relative change measured for the comb drives may be explained by their different cross-sectional profile. For example, a corrosive agent may permeate the 3 - $\mu$ m-wide mechanical springs in the comb drives more readily than it may permeate the 20 - $\mu \mathrm{m}$-wide microcantilever structures. That is, comb-drive structures may be readily corroded from all sides, whereas the microcantilevers are corroded from their top and bottom surfaces only.

The measurable etch rates (Tables III and VI) represent specimens with and without metal present having different thicknesses, also suggesting the influence of galvanic corrosion. The difference in electrochemical potential between gold and polyand single-crystalline [9], [11], [13], [14] Si has been measured previously, and the values fall on the electrochemical profile for PS generation. One effect of such corrosion seen here (Table VI) is the consumption of polySi. Removal of material is significant because, for example, the stiffness of a cantilever beam depends on its area moment, i.e., the thickness cubed.

Similar to Table VI, a change in TTSG with no associated change in IPS is noted in the literature of externally anodized PS [55]. This is explained as the result of the expanded lattice coefficient for PS, which is free to expand in the out-of-plane direction but is constrained in the in-plane direction. Measured increase in lattice parameter in the out-of-plane direction has been correlated with surface oxidation [55], [56], the presence of $\mathrm{Si}-\mathrm{H}$ and $\mathrm{Si}-\mathrm{H}_{2}$ termination [57], [58], and absorbed water [57] at the porous surface layer. While PS tends to grow as an epitaxial single crystal [55], the lattice misfit between the interior Si and exterior PS layers causes out-of-plane curvature as in a multilayer composite structure [55]. Lattice misfit could explain the data (Table VI), if the substrate limited ionic current resulting in different morphology (lattice coefficients) for the top and bottom surfaces. Influence may also come from other through-thickness variation including strain energy, grain morphology, and grain density.

A change in the residual strain cannot explain the change in $f_{R}$ measured in the experiments summarized in Table VI. Even for specimens contacted to metal, TTSG (and IPS) do not demonstrate a pronounced dependence on HF immersion time. Also, the quantitative magnitude of change in curvature is not sufficiently significant. Further, the polySi layers exhibiting the most significant change in curvature do not correspond to those exhibiting the greatest change in $f_{R}$. Therefore, the beams' curvature was not found to influence $f_{R}$. On the other hand, IPS is consistent with the vendor's measured values and was not seen to depend on the use of metal. Therefore, while residual strains can hold an influence over the stiffness of a mechanical resonator, they were not found to greatly contribute to the results in Table VI.

Increased resistance in the poly-0 electrical interconnects Table VI could affect $f_{R}$, for example, if it enabled the interconnect leads to acts as a low-pass filter. Specifically, a low-pass filter can attenuate and phase-shift the actuation signal, masking the characteristics of mechanical resonance. However, when metal was connected to the microcantilever resonance structures, the measured decrease in $f_{R}$ was very consistent within each array of specimens despite the beams' different lengths (Fig. 3). That is, the relative (percent) decrease in $f_{R}$ was nearly identical for all beams within the same array, even though the actual $f_{R}$ of the individual beams was 
TABLE VI

Qualitative Summary of Results for SPECIMENS CONNECTED to GOLd While EXPOSED to THE HF-BASED ChemistRIES

\begin{tabular}{|c|c|c|c|c|c|c|c|}
\hline Etchant & $\begin{array}{c}\text { Change in } \\
\text { Mechanical } \\
\text { Resonance }\end{array}$ & Etch Rate & $\begin{array}{c}\text { Change in } \\
\text { TTSG }\end{array}$ & $\begin{array}{c}\text { Change in } \\
\text { IPS }\end{array}$ & $\begin{array}{c}\text { Change in } \\
\text { Electrical } \\
\text { Resistance }\end{array}$ & $\begin{array}{c}\text { Change in } \\
\text { Hardness \& } \\
\text { Modulus }\end{array}$ & $\begin{array}{c}\text { Change in } \\
\text { Surface } \\
\text { Morphology }\end{array}$ \\
\hline \hline UDHF & Minimal & Minimal & Moderate & None & Significant & Moderate & Minimal \\
\hline $4: 1(\mathrm{UDHF}: \mathrm{HCl})$ & Minimal & Minimal & Moderate & None & Minimal & Minimal & Minimal \\
\hline $4: 1(\mathrm{UDHF}:$ Ethanol) & Minimal & Minimal & Moderate & None & Significant & N/A & Minimal \\
\hline $1: 1(\mathrm{UDHF}:$ :thanol) & Significant & Moderate & Significant & None & Minimal & Significant & Moderate \\
\hline $1: 1\left(\mathrm{UDHF}: \mathrm{H}_{2} \mathrm{O}\right)$ & Moderate & Moderate & Significant & None & Moderate & Significant & Moderate \\
\hline $1: 1\left(\mathrm{UDHF}: \mathrm{NH}_{4} \mathrm{~F}\right)$ & Significant & Significant & Minimal & None & Significant & Significant & Significant \\
\hline 20:1 (UDHF:Triton) & Significant & Moderate & Significant & None & Moderate & Significant & Moderate \\
\hline Vapor $\mathrm{HF}$ & None & Minimal & None & None & Neglible & None & Minimal \\
\hline
\end{tabular}

very different. Furthermore, in our research, we have observed thermal [34], [35] and electrostatic [36] actuators that did not be operate after prolonged aqueous HF chemical processing. The increased resistance measured in the experiments is not thought to greatly influence $f_{R}$, except when the electrical interconnects were damaged during the most prolonged immersions in the HF solutions. In these cases, $f_{R}$ was not shifted but rather the structures were rendered nonfunctional.

What is the cause of the increase in electrical resistance? The results might be explained if the nature of the physical damage is similar to the results seen in porous polySi research [20], where polySi is attacked along the grain boundaries. If corrosion is sufficiently extensive, grain boundaries become severed, decreasing the volume of material available as a path for electrical conduction. Given sufficient exposure time, this mechanism would effectively sever a trace at one or more locations along its length. Increased resistance might also be explained if the corrosion process results in the leaching of phosphorus dopant. Note that the possibility of dopant reduction has not been investigated directly, but it would require diffusion of phosphorus within the polySi at room temperature. Also, measured resistance is seen to remain ohmic in Fig. 5 (in some cases, slightly increasing possibly as the result of Joule heating) suggesting that ample dopant remains. Based on the results in Table VI, as well as current work with single crystal $\mathrm{Si}$ on insulator test structures [59], the effects of grain delineation are thought to dominate over thickness and dopant reduction regarding the increase in electrical resistance.

The results of indentation further demonstrate the mechanical degradation of poly-1 (Table VI), although material integrity is less affected than the poly-0 [51]. From the indentation measurements, there is an evidence of direct corrosion as well as galvanic corrosion of polySi in HF (Fig. 6 and Table V). Furthermore, the measured hardness of poly-1 is in many cases decreased, being less than that of a thermal oxide grown on an Si wafer (Fig. 7). Note that the nominal hardness of Si and $\mathrm{SiO}_{2}$ are $\sim 12$ and $\sim 10 \mathrm{GPa}$, respectively, and the hardness measured for PS was $\leq 3 \mathrm{GPa}$. Therefore, the presence of a thick "native" oxide layer (similar to our 57-nm $\mathrm{SiO}_{2}$ reference specimen) would not be expected to greatly influence the mechanical hardness of silicon, since $\mathrm{SiO}_{2}$ is of similar hardness. The presence of a porous surface layer would, however, readily reduce the hardness of silicon since it is substantially softer than $\mathrm{Si}$. In other words, the indentation data suggests that the corrosion of polySi under the conditions examined here occurs through the formation of PS and not the formation of a thick oxide layer, i.e., electropolishing. From indentation, the corrosion of polySi is seen to readily affect the surface of the material, however, it cannot be determined how deep the extent of damage extends to the interior of the material because of the small sample volume examined using the technique.

Similar to the indentation data (Table VI), the change in morphology of poly-1 may be compared to that seen for poly-0. For some chemistries, both material layers are quite affected (Fig. 8 and [51]). When viewed from either straight-on or oblique perspectives, attack on the surface and grain delineation is seen for many of the chemistries utilized (Figs. 8 and 9). In the surface morphology characterization, there is the evidence of the direct corrosion as well as galvanic corrosion of polySi in HF. Additionally, when viewed at sufficiently high magnification, the presence of a nanoscale surface porosity is observed on poly-1 (Fig. 9) and poly-0 [51] specimens connected to metal. The size of these pores is consistent with the PS literature, where pore sizes ranging from two to tens of nanometers in diameter have been seen [60]. The surface morphology data in Table VI suggests that the immersion of polySi in HF-based solutions results in its dissolution through the formation of a PS surface layer. The process of dissolution would be expected to reduce $f_{R}$, for example, through decreased material thickness and modulus as described previously.

The parameters examined provide a consistent explanation for the measured decrease in $f_{R}$, with primary influence occurring as the result of the surface attack and grain delineation, facilitated by the formation of a PS layer at the material's surface. In particular, the use of the connected metal layers is thought to facilitate the corrosion process. For example, the surface morphology of many of the specimens is of a similar appearance with and without metal being used (Fig. 8 and Table IV), yet substantial change in $f_{R}$ is often only measured when metal is present (Figs. 4 and 6 and Table II). The presence of metal is, therefore, thought to greatly increase the extent of corrosion, driving damage deeper into the material (Fig. 9). In the literature, the presence of an amorphous oxide layer has been observed on polySi subject to HF immersion [7]-[11]. This morphology may come about as the result of the oxidation of a PS surface layer during subsequent postprocessing or upon exposure to the ambient environment. Note that a PS surface layer might be naturally "amorphized" by polySi, since many of the adjacent grains are of different orientation and of a small size such that a stable pore diameter may not establish throughout the material. 
Compared to Fig. 11, the decrease in $f_{R}$ correlates with the measured thickness for the PS layer (Fig. 9). This reaffirms that the experimental data does not fall to the right of Fig. 11, where change in $f_{R}$ becomes dominated by the loss of mass and not mechanical stiffness. In the right of Fig. 11, $f_{R}$ might be expected to increase with immersion time, as the PS layer becomes thicker. In many cases, the effective modulus of the PS exterior layer in Fig. 11 is not as great as that measured during indentation (Table V). Possible explanations include the following: 1) the material removal is so complete that the thickness of the beam is effectively decreased and 2) the polySi interior is affected and decreased during HF immersion. An etch rate, i.e., complete material removal, was measured on some poly-1 structures. In the literature, however, attack deep into polySi results from attack along grain boundaries and the formation of porous veins and voided regions of material [9], [20]. In addition to the general results (Fig. 11), which apply to the many chemistries and immersion times examined, greater detail can be obtained if a particular data point (resonant frequency at a specific immersion time) is chosen, so as to ascertain if the bulk polySi material has been compromised in addition to the corrosion at the free surfaces. Further, additional composite layers might be utilized to better account for material property gradients and/or material consumption could be considered outright $\left(t_{\mathrm{pSi}}\right.$ is decreased). At this point, a more complete understanding and definitively accurate analysis requires TEM characterization, yet to be performed.

Based on all of the measured data, the different chemistries used in the experiments can now be compared. For the first three chemistries examined in Table VI, there is a minimal mechanical and morphological impact, but significant electrical impact, when connected metal is present. Furthermore, there was evidence of localized damage for these chemistries, both optically [51] and using electron microscopy [61]. The pure UDHF as well as the (4:1) UDHF : $\mathrm{C}_{2} \mathrm{H}_{6} \mathrm{O}$ mixtures are believed to effect the polySi based on the inadequate wetting at its surface except at very localized instances. Recall that hydrogen evolution will result in the formation of bubbles at the surface of polySi limiting surface wetting if a surfactant is not used [15]. The UDHF : $\mathrm{HCl}$ mixture likely yields surface wetting characteristics similar to the other two chemistries, with differences facilitated by the presence of the Cl-ion. Note that UDHF : $\mathrm{HCl}$ was the best wet chemistry used in the experiments, i.e., minimal mechanical and electrical damage.

Three other chemistries may be grouped together, based on their similar results in Table VI. These include $(1: 1) \quad \mathrm{UDHF}: \mathrm{C}_{2} \mathrm{H}_{6} \mathrm{O}$, (1:1) UDHF : $\mathrm{H}_{2} \mathrm{O}$, and $(20: 1)$ UDHF : triton-X, which are associated based on their similar mechanical performance (resonance and indentation) and shared morphological likeness. Two of the added chemicals, $\mathrm{C}_{2} \mathrm{H}_{6} \mathrm{O}$ and triton, are known surfactants. These chemicals should aid in surface wetting (and removal of $\mathrm{H}_{2}$ bubbles) so long as the solution is mixed in correct proportion. For example, a sufficient amount of $\mathrm{C}_{2} \mathrm{H}_{6} \mathrm{O}$ must be added in order for it to perform as a surfactant (Table VI and [15]). This points out that the stoichiometry of any of the solutions (Table VI) may be tailored to produce specific results, i.e., none are necessarily optimized. $\mathrm{H}_{2} \mathrm{O}$ has been identified as an oxidizing agent, affecting bare Si wafer specimens if given sufficient time [23]. When water dissociates in solution, the resulting polar hydroxide ions attack the thermodynamically unstable $\mathrm{Si}-\mathrm{H}$ bonds at the polySi surface [39], forming lower energy $\mathrm{Si}-\mathrm{OH}$ bonds and rendering the surface vulnerable to the even more polar F-ion.

Of all of the chemistries examined, vapor HF was seen to result in the least difference when connected metal was present (Table VI). Use of vapor HF may minimize the electrolytic nature (ionic current) of the chemical cell, thereby preventing the damaging anodic current. Some damage to the surface was seen in Fig. 8, perhaps because sufficient monolayers of $\mathrm{H}_{2} \mathrm{O}$ must be present to initiate and continue the etching process [62]. Note that the vapor HF specimens demonstrate that the corrosion damage is unique to HF, since these parts were subsequently exposed to all of the other postprocessing solvents, with no major degradation in performance observed afterwards.

On the other hand, $\mathrm{NH}_{4} \mathrm{~F}$ was seen to cause the most damage of any of the chemistries examined in Table VI, even causing corrosion when no metal was used. Outright damage is consistent with the literature [63] and $\mathrm{NH}_{4} \mathrm{~F}$ is sometimes used to intentionally roughen polySi, altering its surface adhesion characteristics [25]. When UDHF: $\mathrm{NH}_{4} \mathrm{~F}$ is combined with UDHF : $\mathrm{H}_{2} \mathrm{O}$, another influential solution in Table VI, one obtains BOE. Therefore, brief immersion in BOE to strip native oxide is expected to damage the surface of polySi, perhaps making it more vulnerable to corrosion in other chemistries.

Given the long immersion times used in the experiments (Table I), one may question their applicability. When PSG is used, etch times in HF may be as brief as 1.5 min [5], while thermal oxides may be etched in diluted HF solutions for more than $1 \mathrm{~h}$. Note also for some miniature scale applications, there may be instances where the use of so-called "etch release holes" to minimize exposure time to HF cannot be used and prolonged exposure to HF is required. In other postprocessing techniques such as flip-chip bonding [4], lengthy immersion in HF may be required. Last, the use of very compliant flexures (e.g., $1 \times 1 \mathrm{~m}^{2}$ cross sectional), containing minimal material, may be required. Therefore, long etch times as in our experiments may under represent the effects of corrosion. That said, it would be misleading to advocate that the significant influence will occur every time a composite microsystems component is exposed to HF. Instead, corrosion damage in HF-based solution very much depends on the relative surface areas, exposure times, dopant concentration [60], as well as the stochastic nature of the electrochemical dissolution process.

Based on the experiments summarized in Table VI, galvanic corrosion has the potential to impose upon the material properties, design, performance, lifetime (fatigue), tribology (friction/wear), manufacture, and required operating environment of microscale and nanoscale devices. A measurable corrosion rate suggests that device dimensions may differ from their nominal values. This would affect the design and performance of a miniaturized structure, i.e., its mechanical stiffness. In addition to porosity or preferred texture, corrosion may explain why the elastic modulus of polySi measured by research groups is sometimes outside of the isostress and isostrain limits [48] of Si, calculated to be 159 and $165 \mathrm{GPa}$, respectively. Another concern 
is the change in surface morphology, which will affect device tribology and adhesion ("stiction") characteristics. Increase in roughness and decrease in hardness would affect wear rate and friction at surfaces in mechanical contact. The increase in surface roughness would normally be expected to decrease surface-to-surface adhesion, based on an increased effective surface separation distance resulting in decreased attractive surface forces. As a final example, the roughness and grain boundary separations seen after HF immersion (Table IV and Fig. 8) are of the same order of magnitude as suggested in the literature for critical flaw sizes, i.e., $30-115 \mathrm{~nm}$ [11], [64]. This would be expected to influence the fracture and fatigue properties of polySi.

\section{CONCLUSION}

In a comprehensive and systematic study, we have investigated the change in the performance of polySi structures following immersion in various HF-based solutions. To illustrate our results, explore their root cause, and identify possible implications, we focused on mechanically actuated microcantilever structures. Key results include the following. A decrease in the mechanical frequency of resonance $\left(f_{R}\right)$ was measured for the MEMS test structures. Decrease in $f_{R}$ is seen to occur in proportion to the immersion time for several HF-based solutions. Change in $f_{R}$ is greatest for those beams electrically contacted to metal (gold), suggesting an electrochemical aided dissolution process, i.e., galvanic corrosion. A similar time-dependent decrease in $f_{R}$ was measured in comb-drive structures. Likewise, influence can be seen in indentation testing, suggesting that the mechanical properties of the polySi (modulus and hardness) are affected and contribute to the decrease in $f_{R}$. The magnitude of decrease in $f_{R}$ for the eight different HF-based chemistries utilized ranged from minimal, i.e., $<2 \%$ for vapor $\mathrm{HF}$ and UDHF : $\mathrm{HCl}$, to severe, i.e., $>25 \%$ for UDHF : $\mathrm{C}_{2} \mathrm{H}_{6} \mathrm{O}$ or UDHF: $\mathrm{NH}_{4} \mathrm{~F}$. Last, while metal is greatly influential, it is not always required to facilitate the corrosion of polySi, particularly for the UDHF : $\mathrm{NH}_{4} \mathrm{~F}$ chemistry.

Change in $f_{R}$ was not significantly influenced by other factors, including in-plane-oriented residual strain, throughthickness-oriented strain gradient (curvature), or the electrical resistance of polySi interconnects. In-plane strain did not significantly vary between specimens with and without metal present. Through-thickness strain gradient demonstrated influence when metal was utilized, but was not determined to be of significant magnitude and did not demonstrate the necessary time-dependent nature to be related to $f_{R}$. Change in electrical resistance was in some cases very significant, enough to compromise electrical connectivity to the structures, for example, rendering resonator structures nonfunctional. However, change in electrical resistance was not found to otherwise affect $f_{R}$. Instead, net removal of material (changing in the beam thickness) as well as the alteration of material properties (changing the effective modulus) are seen to be primarily responsible for the change in $f_{R}$.

The measured change in $f_{R}$ can be correlated to a physical basis. The experiments, including direct examination of the surface morphology suggest that the alteration of $f_{R}$ is related to the autonomous dissolution of polySi facilitated through the formation of the PS layer at the near surface. Nanoscale pores roughly $5-10 \mathrm{~nm}$ in diameter as well as grain delineation were seen at surface and found to extend to some depth within fractured beam specimens. Additionally, the indentation of the various specimens is more comparable to PS than to single crystal $\mathrm{Si}$ or a thin thermal oxide. Last, analysis suggests that the decrease in $f_{R}$ is dominated by the decrease in mechanical stiffness for the PS surface layers and not the loss of mass associated with the dissolution of polySi. Aided by electrochemistry, corrosion in HF-based solutions may at times greatly impose upon the material properties, design, performance, lifetime, tribology, manufacture, and required operating environment of microscale and nanoscale devices.

\section{ACKNOWLEDGMENT}

The authors would like to thank D. Serrell at the National Institute for Standards and Technology (NIST) and the University of Colorado, Boulder, for help in generating a thermal oxide reference specimen.

\section{REFERENCES}

[1] T. A. Lober and R. T. Howe, "Surface micromaching processes for electrostatic microactuator fabrication," in Proc. IEEE MEMS, 1990 , pp. 59-62.

[2] J. A. Walker, K. J. Gabriel, and M. Mehregany, "Mechanical integrity of polysilicon films exposed to hydroflouric acid solutions," in Proc. IEEE MEMS, 1990, pp. 56-60.

[3] D. J. Monk, P. A. Krulevitch, R. T. Howe, and G. C. Johnson, "Stresscorrosion cracking and blistering of thin polycrystalline silicon films in hydrofluoric acid," in Proc. Mater. Res. Soc. Symp., 1993, vol. 308 , pp. 641-646.

[4] R. Irwin, W. Zhang, K. Harsh, and Y. C. Lee, "Quick prototyping of flip-chip assembly with MEMS," in Proc. IEEE RAWCON, 1998, pp. 293-296.

[5] E. Chan, K. Garikipati, and R. Dutton, "Comprehensive static characterization of vertical electrostatically actuated polysilicon beams," IEEE Design Test Comput., vol. 16, no. 4, pp. 58-65, Oct.-Dec. 1999.

[6] T. Tsuchiya, O. Tabat, J. Sakata, and Y. Taga, "Specimen size effect on tensile strength of surface-micromachined polycrystalline silicon thin films," J. Microelectromech. Syst., vol. 7, no. 1, pp. 106-113, Feb. 1998.

[7] I. Chasiotis and W. G. Knauss, "The influence of fabrication governed surface conditions on the mechanical strength of thin film materials," in Proc. Mater. Res. Soc. Symp., 2001, vol. 657, pp. EE2.2.1-EE2.2.6.

[8] I. Chasiotis and W. G. Knauss, "The mechanical strength of polysilicon films: Part 1. The influence of fabrication governed surface conditions," J. Mech. Phys. Solids, vol. 51, pp. 1533-1550, 2001

[9] H. Kahn, C. Deeb, I. Chasiotis, and A. H. Heuer, "Anodic oxidation during MEMS processing of silicon and polysilicon: Native oxides can be thicker than you think," J. Microelectromech. Syst., vol. 14, no. 5 , pp. 914-923, Oct. 2005.

[10] M. Huh, Y. Yu, H. Kahn, J. H. Payer, and A. H. Heuer, "Galvanic corrosion during processing of polysilicon microelectromechanical systems: The effect of Au metallization," J. Electrochem. Soc., vol. 153, no. 7, pp. G644-G649, 2006.

[11] O. N. Pierron, D. D. Macdonald, and C. L. Muhlstein, "Galvanic effects in Si-based microelectromechanical systems: Thick oxide formation and its implications for fatigue reliability," Appl. Phys. Lett., vol. 78, no. 21, pp. 211919-211921, 2005.

[12] Z. Zhang, M. M. Lerner, T. Alekel, and D. A. Keszler, "Formation of a photoluminescent surface on $\mathrm{n}-\mathrm{Si}$ by irradiation without externally applied potential," J. Electrochem. Soc., vol. 140, no. 6, pp. L97-L98, 1993.

[13] C. Ashruf, P. French, P. Bressers, and J. Kelly, "Galvanic porous silicon formation without external contacts," Sens. Actuators A, Phys., vol. 74, pp. 118-122, 1999.

[14] X. Xia, C. Ashruf, P. French, and J. Kelly, "Galvanic cell formation in silicon/metal contacts: The effect on silicon surface morphology," Chem. Mater., vol. 12, pp. 1671-1678, 2000. 
[15] O. Bisi, S. Ossicini, and L. Pavesi, "Porous silicon: A quantum sponge structure for silicon based optoelectronics," Surf. Sci. Rep., vol. 38, pp. $1-126,2000$.

[16] R. L. Smith and S. D. Collins, "Porous silicon formation mechanisms," J. Appl. Phys., vol. 71, no. 8, pp. R1-R22, 1992.

[17] L. Canham, Properties of Porous Silicon. Piscataway, NJ: IEEE, 1997.

[18] X. G. Zhang, S. D. Collins, and R. L. Smith, "Porous silicon formation and electropolishing of silicon by anodic polarization in HF solution," J. Electrochem. Soc., vol. 136, no. 5, pp. 1561-1565, 1989.

[19] X. G. Zhang, "Mechanism of pore formation on n-type silicon," J. Electrochem. Soc., vol. 138, no. 12, pp. 3750-3756, 1991.

[20] P. Guyander, P. Joubert, M. Guendouz, C. Beau, and M. Sarrett, "Effect of grain boundaries on the formation of luminescent porous silicon from polycrystalline silicon films," Appl. Phys. Lett., vol. 65, no. 14, pp. $1787-1789,1994$.

[21] N. M Kalhoran, F. Namavar, and H. P. Maruska, "Optoelectronic applications of porous polycrystalline silicon," Appl. Phys. Lett., vol. 63, no. 19, pp. 2661-2663, 1993.

[22] P. Joubert, A. Abouliatim, P. Guyander, D. Briand, B. Lambert, and M. Guendouz, "Growth and luminescence of n-type polycrystalline silicon," Thin Solid Films, vol. 255, pp. 96-98, 1995.

[23] G. Willeke and K. Kellerman, "Crystalline silicon etching in quiescent concentrated aqueous HF solutions," Semicond. Sci. Technol., vol. 11, pp. 415-421, 1996.

[24] K. Kellerman and G. Willeke, "Observation of silicon etch pit formation in quiescent concentrated aqueous HF solutions," Mater. Lett., vol. 19, pp. 7-12, 1994.

[25] M. Houston, R. Howe, and R. Maboudian, "Effect of hydrogen termination on the work of adhesion between rough polycrystalline silicon surfaces," J. Appl. Phys., vol. 81, no. 8, pp. 3474-3483, 1997.

[26] P. Allonge, "Porous silicon formation mechanisms," in Properties of Porous Silicon, L. Canham, Ed. Piscataway, NJ: IEEE, 1997, pp. 3-11.

[27] B. C. Chung, G. A. Marshall, C. W. Pearce, and K. P. Yanders, "The prevention of Si pitting in hydrofluoric acid cleaning by additions of hydrochloric acid," J. Electrochem. Soc., vol. 144, no. 2, pp. 652-657, 1997.

[28] S. Zangooie, R. Jansson, and H. Arwin, "Microstructural control of porous silicon by electrochemical etching in mixed $\mathrm{HCl} / \mathrm{HF}$ solutions," Appl. Surf. Sci., vol. 136, no. 1-2, pp. 123-130, 1998.

[29] G. Sotgiu, L. Schirone, and F. Rallo, "On the use of surfactants in the electrochemical preparation of porous silicon," Thin Solid Films, vol. 297, pp. 18-21, 1997.

[30] J. Das, S. M. Hossain, S. Chakraborty, and H. Saha, "Role of parasitics in humidity sensing by porous silicon," Sens. Actuators A, Phys., vol. 94, no. 1-2, pp. 1-9, 2001.

[31] E. J. Connolly, G. M. O'Halloran, H. T. M. Pham, P. M. Sarro, and P. J. French, "Comparison of porous silicon, porous polysilicon, and porous silicon carbide as materials for humidity sensing applications," Sens. Actuators A, Phys., vol. 99, pp. 25-30, 2002.

[32] T. Unagami, "Intrinsic stress in porous silicon layers formed by anodization in HF solution," J. Electrochem. Soc., vol. 144, no. 5, pp. $1835-1838,1997$.

[33] Z. Shen, J. J. Thomas, C. Averbuj, K. M. Broo, M. Englehard, J. E. Crowell, M. G. Finn, and G. Siuzdak, "Porous silicon as a versatile platform for laser desorption/ionization mass spectrometry," Anal. Chem., vol. 73, no. 3, pp. 612-619, 2001.

[34] R. Cragun and L. L. Howell, "Linear thermomechanical microactuators," in Proc. ASME IMECE, 1999, pp. 181-188.

[35] J. R. Reid, V. M. Bright, and J. H. Comtois, "Arrays of thermal microactuators coupled to micro-optical components," in Proc. SPIE-Int. Soc. Opt. Eng., 1996, vol. 2865, pp. 74-82.

[36] W. C. Tang, T. C. H. Nguyen, and R. Howe, "Laterally driven polysilicon resonant microstructures," Sens. Actuators A, Phys., vol. 20, pp. 25-32, 1989.

[37] D. Koester, A. Cowen, R. Mahadevan, M. Stonefeild, and B. Hardy, Poly-MUMPs Design Handbook: Revision 10. Research Triangle Park, NC: MEMSCAP Inc., 2003, pp. 1-10, Paper No. 79295.

[38] R. F. Pierrot, Advanced Semiconductor Materials, ser. Series on SolidState Devices. Reading, MA: Addisorn-Wesley, 1987, vol. XI.

[39] D. Gräf, M. Grunder, and R. Schultz, "Reaction of water with hydrofluoric acid treated silicon (111) and (100)," J. Vac. Sci. Technol. A, Vac. Surf. Films, vol. 7, no. 3, pp. 808-813, 1989.
[40] G. Mulhern, D. Soane, and R. Howe, "Supercritical carbon dioxide drying of microstructures," in Proc. IEEE Transducers, 1993, pp. 296-299.

[41] N. D. Masters, M. P. deBoer, B. D. Jensen, M. S. Baker, and D. Koester, "Side-by-side comparison of passive MEMS strain test structures under residual compression," ASTM Mech. Prop. Struct. Films, vol. 1413, pp. 168-200, 2001.

[42] B. P. van Drieenhuizen, J. F. L. Goosen, P. J. French, and R. F. Wolffenbuttel, "Comparison of techniques for measuring both compressive and tensile stress in films," Sens. Actuators A, Phys., vol. 37-38, pp. 756-765, 1993.

[43] H. N. Wagar and W. Everitt, Integrated Device and Connection Technology. Englewood Cliffs, NJ: Prentice-Hall, 1971, vol. III, pp. 469-473.

[44] M. G. Buehler, S. D. Grant, and W. R. Thurber, "Bridge and van der Pauw sheet resistors for characterizing the line width of conducting layers," J. Electrochem. Soc., vol. 125, no. 4, pp. 650-654, 1978.

[45] W. C. Oliver and G. M. Pharr, "Measurement of hardness and elastic modulus by instrumented indentation: Advances in understanding and refinements to methodology," J. Mater. Res., vol. 19, pp. 3-20, 2004.

[46] D. C. Miller, M. J. Talmage, and K. Gall, "Incipient yielding behavior during indentation for gold thin films before and after annealing," $J$. Mater. Res, vol. 21, no. 9, pp. 2480-2492, 2006.

[47] V. Domnich, D. Ge, and Y. Gogotsi, "Indentation-induced phase transformations in semiconductors," in High-Pressure Surface Science and Engineering. Philadelphia, PA: IOP, 2004.

[48] R. Hill, "The elastic behavior of crystalline aggregate," Proc. Phys. Soc. $A$, vol. 65, no. 389, pp. 349-354, 1952.

[49] D. C. Miller, K. Gall, and C. R. Stoldt, "Mechanical effects of galvanic corrosion on thin film polysilicon," in Proc. ASME IMECE, 2005, p. 79295.

[50] M. R. McGurk and T. F. Page, "Using the $P-d^{2}$ analysis to deconvolute the nanoindentation response of hard-coated systems," J. Mater. Res., vol. 14, pp. 2283-2295, 1999.

[51] D. C. Miller, W. L. Hughes, Z. L. Wang, K. Gall, and C. R. Stoldt, "Galvanic corrosion: A microsystems device integrity and reliability concern," in Proc. SPIE-Int. Soc. Opt. Eng., vol. 6111, no. 5, pp. 1-12.

[52] R. Jones, Mechanics of Composite Materials, 2nd ed. Philadelphia, PA: Taylor \& Francis, 1999, pp. 224-229.

[53] D. C. Miller, C. F. Herrmann, H. J. Maier, S. M. George, C. R. Stoldt, and K. Gall, "Thermo-mechanical evolution of multilayer thin films, Part 1: Mechanical behavior of $\mathrm{Au} / \mathrm{Cr} / \mathrm{Si}$ microcantilevers," Thin Solid Films, to be published.

[54] L. J. Gibson and M. F. Ashby, Cellular Solids: Structures and Properties, 2nd ed. Cambridge, U.K.: Cambridge Univ. Press, 1997.

[55] K. Barla, R. Herino, G. Bomchi, and J. C. Pfister, "Determination of lattice parameter and elastic properties of porous silicon by X-ray diffraction," J. Cryst. Growth, vol. 64, pp. 727-752, 1984.

[56] H. Sugiyama and O. Nittono, "Annealing effect on lattice distortion in anodized porous silicon layers," J. Appl. Phys, vol. 28, no. 11, pp. 2013-2016, 1989.

[57] T. Unagami, "Oxidation of porous silicon and properties of its oxide film," J. Appl. Phys., vol. 19, no. 2, pp. 231-241, 1980.

[58] V. Labunov, V. Bondarenko, L. Glinekko, A. Dorofeev, and L. Tabulina, "Heat treatment effect on porous silicon," Thin Solid Films, vol. 137, pp. 123-134, 1986.

[59] D. C. Miller, B. L. Boyce, and K. Gall, "Exploring the mechanical properties of Ag nanowires and Au thin films," presented at the Mater. Res. Soc. Symp., 2006, Z4.2, unpublished.

[60] R. Herino, G. Bomchil, K. Barla, and C. Bertrand, "Porosity and pore size distributions of porous silicon layers," J. Electrochem. Soc., vol. 134, no. 8, pp. 1994-2000, 1987.

[61] D. C. Miller, K. Gall, and C. R. Stoldt, "Galvanic corrosion of thin film polysilicon: Morphological, electrical and mechanical effects," Electrochem. Sol. State Lett., vol. 8, pp. G223-G226, 2005.

[62] W. I. Jang, C. A. Choi, M. L. Lee, C. H. Jun, and Y. T. Kim, "Fabrication of MEMS devices by using anhydrous HF gas-phase etching with alcoholic vapor," J. Micromech. Microeng., vol. 12, pp. 297-306, 2002.

[63] W. Kern, "Cleaning solutions based on hydrogen peroxide for use in silicon semiconductor technology," RCA Rev., vol. 31, no. 2, pp. 187-206, 1970.

[64] J. Bagdahn, W. Sharpe, and O. Jadaan, "Fracture strength of polysilicon at stress concentrations," J. Microelectromech. Syst., vol. 12, no. 3, pp. 302-312, Jun. 2003. 


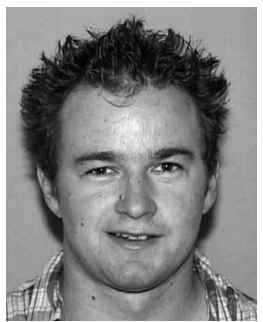

David C. Miller received the Ph.D. degree in mechanical science and engineering from the University of Colorado, Boulder, in 2006.

He has worked at Network Photonics, where he helped develop a MEMS-based wavelength switch for optical telecommunications. His current research interests include materials science, solid mechanics, and applications for the microscale and nanoscale.

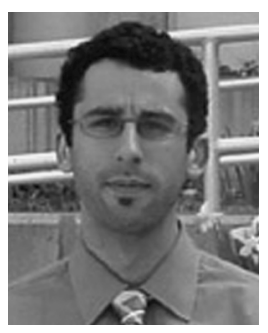

William L. Hughes was born in Raleigh, NC. He received the B.S. degree in materials science and engineering from the Virginia Polytechnic Institute and State University (Virginia Tech), Blacksburg, in 2001 and the Ph.D. degree in materials science and engineering from the Georgia Institute of Technology, Atlanta, in 2006. His dissertation was focused on the synthesis and characterization of nanomaterials for piezoelectric applications.

He is currently an Assistant Professor at California Polytechnic State University (Cal Poly), San Luis Obispo. His current research is focused on service learning, as well as the development of novel nanomaterials.

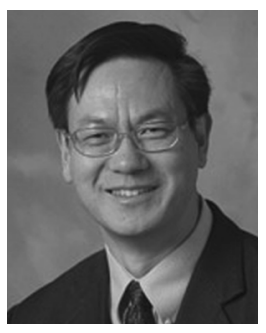

Zhong-Lin Wang received the Ph.D. degree in physics from Arizona State University, Tempe, in 1987.

After a year of postdoctoral study at the State University of New York at Stony Brook, in 1988, he received the Research Fellowship by the Cavendish Laboratory, University of Cambridge, Cambridge, U.K. He received a U.S. Department of Energy Research Fellowship at Oak Ridge National Laboratory in 1989, and he was appointed as a Research Associate Professor by the University of Tennessee in 1990. In 1993, he joined the National Institute of Standards and Technology (NIST) to set up the microscopy facility. He joined the Georgia Institute of Technology, Atlanta, in 1995.

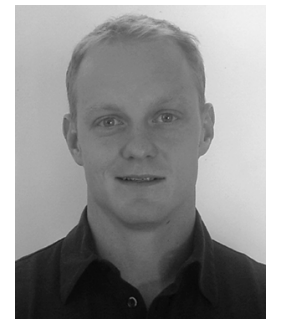

Ken Gall received the Ph.D. degree in mechanical engineering from the University of Illinois at UrbanaChampaign, in 1998.

He spend a year at Sandia National Laboratories, Livermore, CA, and six years at the University of Colorado, Boulder. He is currently an Associate Professor at the School of Materials Science and Mechanical Engineering, the Georgia Institute of Technology, Atlanta. His technical expertise pertains to the mechanical behavior of materials for use in emerging technologies. He has general interests in multiscale experimental and computational methods in materials science, mechanical engineering, and bioengineering. His specific interests include metallic and polymer biomaterials, nanometer scale materials, and mechanically active materials.

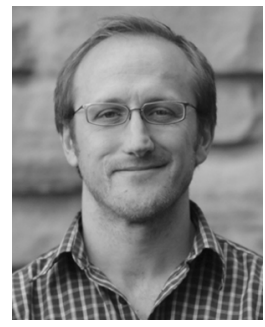

Conrad R. Stoldt received the Ph.D. degree in physical chemistry and surface science from Iowa State University, Ames, in 1999,

$\mathrm{He}$ is the Assistant Professor of Mechanical Engineering at the University of Colorado, Boulder. He served as a Postdoctoral Associate in Chemical and Mechanical Engineering at the University of California, Berkeley, from 1999 to 2002, where he studied fullerene surface reactions, the vapor phase etching of group $I-V$ materials, and developed a $\mathrm{SiC}$ deposition process for MEMS-based micromechanical structures. He is an author of over 30 refereed journal articles and book chapters in the fields of solid-state physics, materials processing, MEMS, and surface science. His research interests include the development of new materials and processing methods for MEMS and NEMS devices. Further, he is developing new nanoscale material systems for molecular imaging, photovoltaic, and microwave applications. 